Research Article

\title{
Moringa oleifera Leaf Extract-Mediated Green Synthesis of Nanostructured Alkaline Earth Oxide (MgO) and Its Physicochemical Properties
}

\author{
Archana Venkatachalam ${ }^{(D},{ }^{1}$ Joseph Prince Jesuraj ${ }^{D},{ }^{1}$ and kalainathan Sivaperuman ${ }^{2}{ }^{2}$ \\ ${ }^{1}$ Department of Physics, University College of Engineering, Anna University (BIT Campus), Tiruchirappalli, Tamil Nadu, India \\ ${ }^{2}$ Centre for Nanotechnology Research, VIT, Vellore, Tamil Nadu, India
}

Correspondence should be addressed to Archana Venkatachalam; c.v.archanavenkat@gmail.com

Received 17 June 2020; Accepted 4 June 2021; Published 23 June 2021

Academic Editor: Dario Pasini

Copyright (C) 2021 Archana Venkatachalam et al. This is an open access article distributed under the Creative Commons Attribution License, which permits unrestricted use, distribution, and reproduction in any medium, provided the original work is properly cited.

\begin{abstract}
The magnesium oxide nanoparticles (MgO NPs) were prepared from Moringa oleifera leaf extract. Phytochemicals are derived from plant extract which are served as stabilizing and capping agents. This green route has been attracted owing to speed, reliable, and eco-friendly and cost-effective one. The synthesized magnesium oxide nanoparticles were taken into three different calcination temperatures $\left(500,600\right.$, and $\left.700^{\circ} \mathrm{C}\right)$. The powder X-ray diffraction (PXRD) study shows a pure phase of face-centered cubic structure. Periclase $\mathrm{MgO}$ nanoparticles were prepared. The optical band gap of $\mathrm{MgO}$ nanoparticles is $4.5 \mathrm{eV}$, and its absorption in the UV region was observed by UV-visible spectroscopy (UV-Vis). Photoluminescence spectra have exhibited multicolor emissions were being at UV and visible region due to defect centers (F centers) of MgO nanoparticles. EDX (energy dispersive X-ray spectrum) has given the stoichiometric ratio of $\mathrm{Mg}$ and $\mathrm{O}$. The functional groups have been studied by Fourier transformed infrared spectroscopy (FTIR), surface morphology transformation has been identified by scanning electron microscopy (SEM) studies, and VSM measurements have given the information of diamagnetic nature of $\mathrm{MgO}$ nanoparticles. $\mathrm{H}-\mathrm{R}$ TEM micrographs have confirmed that particles were in nanorange matched with XRD report. Polycrystalline nature has been observed pattern information. TG-DSC characterization revealed phase transition and weight loss information. D-band and G-band of MgO nanoparticles are studied by micro-Raman analysis. Dielectric analysis has proven that MgO nanoparticles will be a promising candidate for linear dielectric ceramics, thermistor. The present resent studies have revealed that $\mathrm{MgO}$ powder will be an economical and promising candidate in superconductor, optoelectronic device, and energy storage applications.
\end{abstract}

\section{Introduction}

Metal oxides are widely employed as catalysts, optical devices, sensors, thermal conductivity enhancers, and energy conversion devices [1-10]. Engineered nanomaterials have unique properties which can be tailored with shape and size, and morphology leads to outstanding properties which are limited to bulk materials. A variety of different structured metal oxides are nanoparticles, wires, tubes, fibers, whiskers, films, layers, triangles, and tetra pods which are most desired structures widely used in technical applications, and its unique structural features are large surface-to-volume ratio, cations with valence states, anions with deficiencies, and depletion of carriers [1]. Magnesium oxides are alkaline earth-based oxide metal is attraction owing to its high economical availability, toxicity, and eco-friendly nature, has been used as inorganic phosphor for optoelectronic devices, biosensors, catalyst. Owing to their defect-induced luminescent property is widely used as solid-state devices [1]. $\mathrm{MgO}$ is the wide band gap insulator and smooth surface features due to this property, and it has been used as sensors, refractory, paint, toxic waste remediation, and superconductors [1].

Phytochemical-mediated synthesis is a green route which has great attention due to novel strategies and alternative to physical and chemical methods [11]. In this type 
of bottom-up approach, where the phytochemicals are stabilized and capped with the metal oxide nanoparticles, the reducing agents involved in nanoparticle synthesis are alkaloids, phenolic compounds, terpenoids, and coenzymes [12]. Biosynthesis route employs simple prokaryotic bacteria to eukaryotes such as fungi, plants, and biogreen synthesis which have a better advantage while comparing microorganisms wherein plant-mediated synthesis is the one-step synthesis, but owing to mutation microorganisms over time, they may lose their ability to synthesize nanoparticles and it is very laborious and time-consuming [13]. Plant-mediated synthesis is the one-step protocol and safe; hence, research on plants has expanded rapidly [11, 14, 15]. Plants as a biological agent served as reducing and capping agents involved in the synthesis process and are eco-friendly $[16,17]$. Every part of the plant can be used for nanoparticle synthesis such as leaves of the plant, stem, straw, flower, and root [16-22]. Here, extracellular methods had been used for the synthesis of nanoparticles which include the use of leaf extract prepared by boiling or crushing of leaves [23-25]. Nanoparticle synthesis using a plant system is the current scenario. Plant-mediated synthesis is not only used for environmental impact but also used to produce large quantities of contaminated free nanoparticles with welldefined morphology and size [26]. The characteristics of the nanoparticles have been influenced by the source of the plant extract because different extracts contain different concentrations and combinations of organic reducing agents, a plant extract-mediated bioreduction involves mixing the aqueous extract with an aqueous solution of the relevant metal salt at room temperature, and it has been completed within a few minutes $[12,27,28]$.

Biogreen $\mathrm{MgO}$ nanoparticles which had been synthesized from various leaves, fruit, and seed have been reported here. Magnesium oxide nanoparticles were synthesized from Clitoria ternatea leaf extract [29], orange fruit waste [30], citrus lemon leaf extract [31], Brassica oleracea and Punica granatum peels [32], Swertia chirayita [33], neem leaf extract [34], Aloe vera extract [35], seeds of Lepidium sativum [36], aqueous leaf extracts of Psidium guajava (P. guajava) [37], Nephelium lappaceum L. peel extract [38], Amaranthus tricolor, Andrographis paniculata and Amaranthus blitum [39], aqueous leaf extracts of betel [30], Artemisia abrotanum herb water extract [40], Parthenium plant extract [41], and fruit extract (Emblica officinalis) [42]. Biosynthesis of magnesium oxide nanoparticles using leaf extract in the present scenario has been reported here. The aqueous magnesium ions when exposed to Moringa oleifera leaf extract are reduced, and magnesium oxide nanoparticles formed. The plant is belonging to the Moringaceae family, and it is distinguished by parietal placentation, 3-valved fruit, elongated, nondehiscent berry and winged seeds, and a medium-sized tree. The botanical name of the tree is Moringa oleifera Lam., and the family consists of the single genus Moringa [43]. It is widely available in India, and it is an essential dietary ingredient of Indian food. The plant contains minerals, proteins, vitamins, amino acids, and phenolics and provides a rich and rare combination of zeatin, quercetin, $\beta$-sitosterol, caffeoylquinic acid, and kaempferol. The leaves contain concentrations of ascorbic acid, oestrogenic substances [44], iron, calcium, phosphorus, copper, vitamins $\mathrm{A}, \mathrm{B}$, and $\mathrm{C}, \alpha$-tocopherol, riboflavin, nicotinic acid, folic acid, pyridoxine, $\beta$-carotene, protein, and in particular essential amino acids such as methionine, cysteine, tryptophan, and lysine [45]. Silver, nickel, and zinc oxide metal nanoparticles had been synthesized from Moringa oleifera leaf extract. Magnesium oxide nanoparticles have not been reported so as per our knowledge. Herein, a simple and economical procedure has adopted for synthesizing nanostructured $\mathrm{MgO}$ using an aqueous leaf extract of Moringa oleifera. To the best of our knowledge, this is the first report to use of an aqueous leaf extract of Moringa oleifera for synthesis of $\mathrm{MgO}$ nanoparticles. The prepared $\mathrm{MgO}$ nanoparticles are characterized using spectroscopic and microscopic techniques. The thermal, magnetic, and dielectric properties of the prepared $\mathrm{MgO}$ nanoparticles have also been studied.

\section{Materials and Methods}

2.1. Material Collection. Homely grown Moringa oleifera leaves had been collected. All the chemicals were purchased from Merck that can be used without further purification $\left(\mathrm{MgCl}_{2} \cdot 6 \mathrm{H}_{2} \mathrm{O}\right.$, and $\left.\mathrm{NaOH}\right)$. The chemicals were used here with AR grade with $98 \%$ of purity. All aqueous solutions were prepared with double distilled water.

\subsection{Moringa oleifera Leaf Extract Preparation Method.} Freshly collected Moringa oleifera leaves were washed thoroughly with double distilled water to remove dust particles, weighed, and transferred into the round bottom flask, and it was mixed with water and refluxed for 40 minutes at 70 degrees at the heating mantle. Then, the extract was filtered by Whatman filter paper (No.1) with several times and kept in sterile bottles under refrigerated conditions for the future use. Moringa oleifera leaves and extract are shown in Figures 1(a) and 1(b).

\subsection{Moringa oleifera Leaf Extract-Mediated Preparation of} $\mathrm{MgO} N$ Ps. In phytochemical-mediated synthesis of $\mathrm{MgO}$ NP fabrication, the extract of Moringa oleifera leaf extract (capping and stabilizing agent) was added to the aqueous solution of $\mathrm{MgCl}_{2} \cdot 6 \mathrm{H}_{2} \mathrm{O}$ and stirred vigorously at room temperature, and then few drops of $\mathrm{NaOH}$ are added under stirring for maintaining appropriate $\mathrm{PH}$ which could be acted as a precipitating agent. The transparent solution changed to yellowish color. After 6 hours, the stirred process was completed, precipitation obtained which was yellowish color colloidal particles at the bottom of the flash which indicates the formation of $\mathrm{Mg}(\mathrm{OH})_{2}$ is shown in Figures 2(a) and 2(b). Then, the colloidal solution was centrifuged several times at $4000 \mathrm{rpm}$ for 15 minutes and washed several times with double distilled water and ethanol to remove impurities. After the washing process, the supernatant was collected and dried overnight in a hot air oven at 70-degree Celsius. The dried samples of $\mathrm{Mg}(\mathrm{OH})_{2}$ were crushed and grounded by mortar and pestle. The grounded 


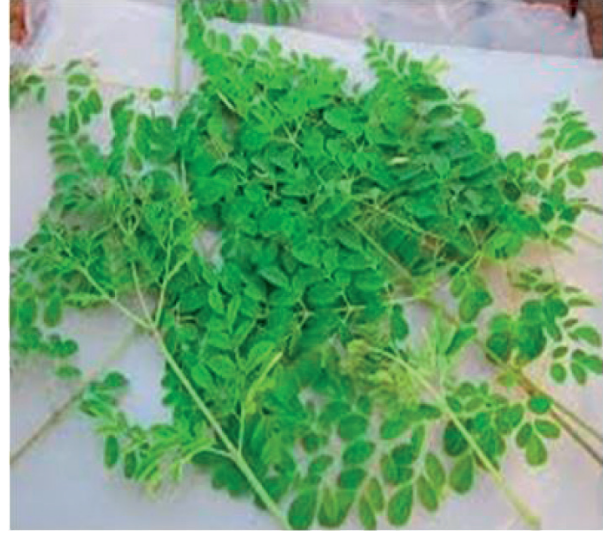

(a)

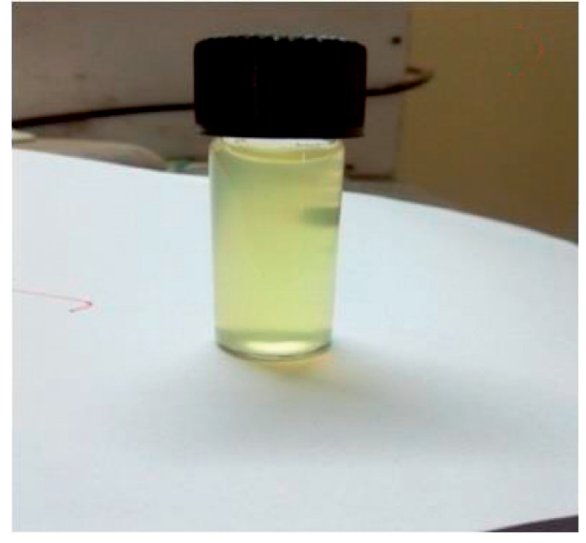

(b)

Figure 1: Moringa oleifera leaves (a) and aqueous Moringa oleifera leaf extract (b).

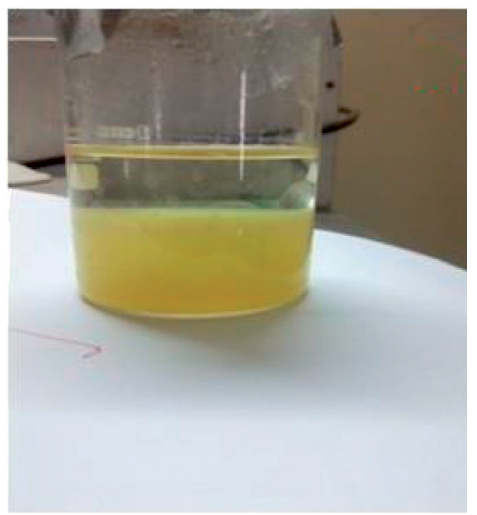

(a)

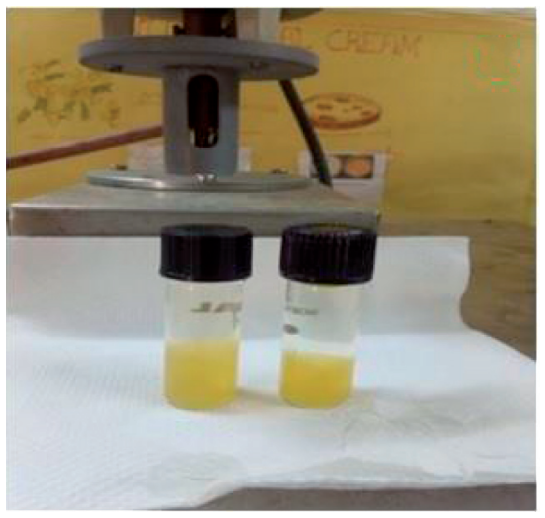

(b)

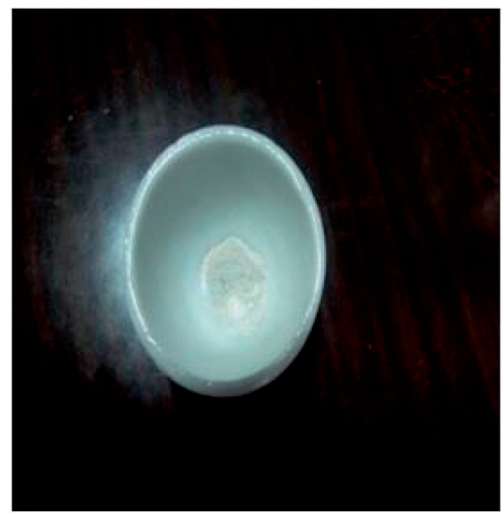

(c)

Figure 2: $\mathrm{Mg}(\mathrm{OH})_{2}$ nanoparticle $(\mathrm{a}, \mathrm{b})$ and $\mathrm{MgO}$ nanopowder (c).

samples were calcinated in a muffle furnace at different temperatures at 500,600 , and $700^{\circ} \mathrm{C}$ for three hours for dehydration, the impurities were removed, and finally, white-colored $\mathrm{MgO}$ nanoparticles were obtained as shown in Figure 2(c). The mechanism of synthesis of $\mathrm{MgO}$ nanoparticles is illustrated in Figure 3.

\section{Material Characterization and Instrumentation}

The calcinated $\mathrm{MgO}$ nanoparticles were analyzed with PAN analytical X'Pert PRO powder X-ray diffractometer with a $\mathrm{CuK} \alpha$ radiation operated at $40 \mathrm{kV}$ and $30 \mathrm{~mA}$ and the wavelength of $\lambda=1.54060 \AA$ in the range $2 \theta=10-80^{\circ}$. The photoluminescence spectra of $\mathrm{MgO}$ nanoparticles studied with $300-700 \mathrm{~nm}$ regions were recorded with Varian Cary Eclipse photoluminescence spectra photometer at room temperature with an excitation wavelength of $320 \mathrm{~nm}$. UVvisible spectroscopic studies have been done by a Shimadzu dual-beam spectrometer. The size of the nanoparticle has been determined by transmission electron microscope (TEM) (FEI Tecnai 20) accelerated at $200 \mathrm{kv}$, morphology of the $\mathrm{MgO}$ was studied by using scanning electron microscope (SEM) (JEOL JSM 6390), and elemental analysis was done by energy dispersive X-ray analysis (EDS) which is attached with SEM X-ray column along with SEM images of nanoparticles. The functional groups were found by the Fourier transform infrared spectrum (FTIR) spectrophotometer (PerklinElmer spectrometer) using $\mathrm{KBr}$ pellets in the spectral range $4000-400 \mathrm{~cm}^{-1}$. Magnetic properties were investigated and performed at room temperature where the vibrating sample magnetometer model is employed and here applied magnetic field sleeping from -15000 to +15000 (Lakeshore, USA, model 740 equipped with magnetic field $2.17 \mathrm{~T}$ ). Thermal properties were analyzed by thermal analyzer NETZSCH STA 449 F3 Jupiter which performs simultaneous TG-DSC measurement on the sample. Dielectric properties were characterized by an AC impedance spectroscopy and dielectric analysis using HIOKI 3532-50 LCR Hi TESTER meter in the frequency range of $50 \mathrm{~Hz}-5 \mathrm{MHz}$.

\section{Results and Discussion}

4.1. Structural Analysis-Powder X-Ray Diffraction (PXRD). The PXRD technique is used for the identification of crystal structure, purity, and crystallinity. The $\mathrm{MgO}$ nanoparticles have been synthesized and then air-dried at a hot air oven, it 


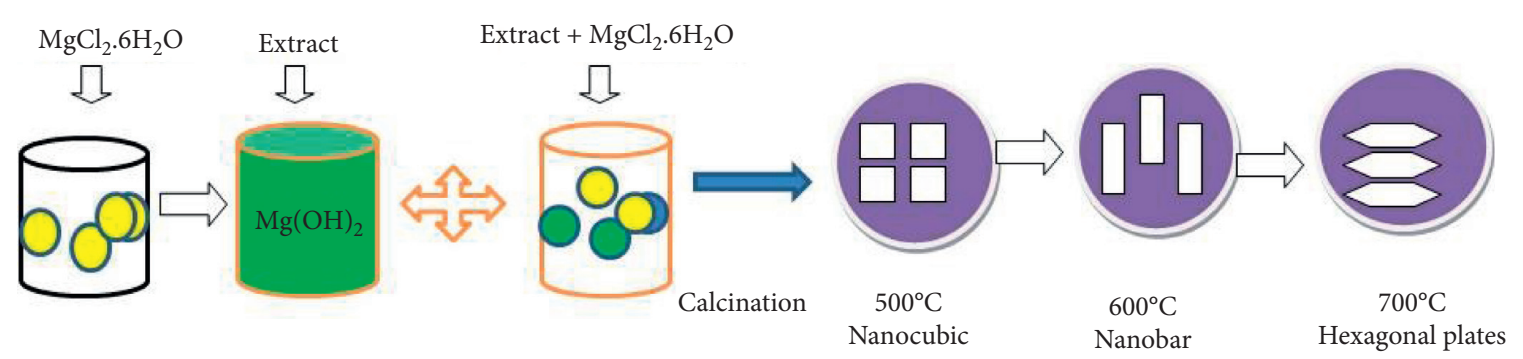

FIGURE 3: Mechanism of synthesis of MgO nanoparticles.

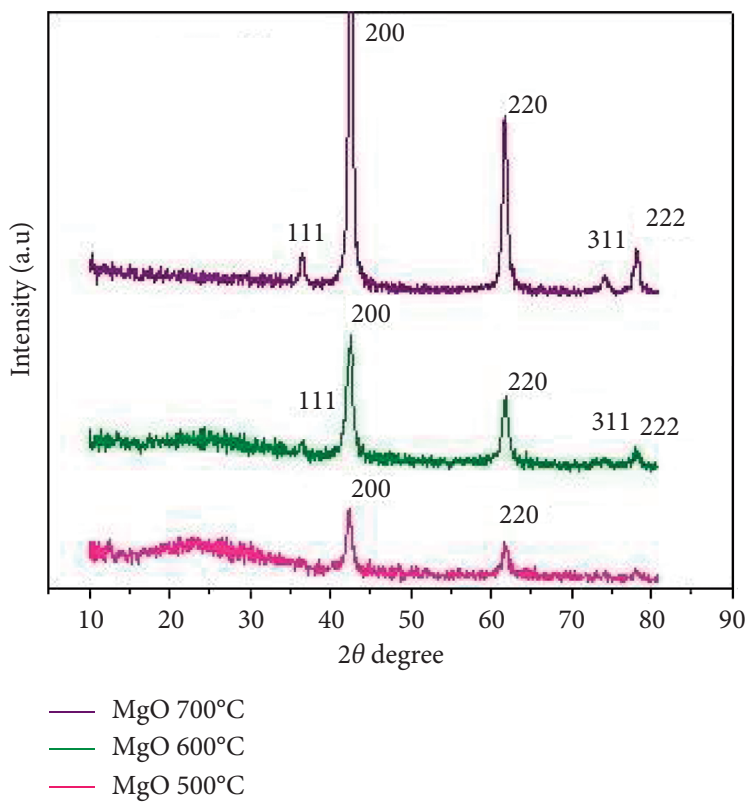

Figure 4: PXRD patterns of $\mathrm{MgO}$ nanoparticles at different calcination temperatures $\left(500,600\right.$, and $\left.700^{\circ} \mathrm{C}\right)$.

was calcinated to different temperatures $(500,600$, and $\left.700^{\circ} \mathrm{C}\right)$, and then it was characterized by PXRD. The patterns of XRD were affirmed that it belongs to the cubic phase of periclase with the Fm3m space group. All peaks were indexed according to the ICDD reference number (01-0750447). The PXRD patterns clearly show that there were no peaks that had disappeared and had not found any additional peaks were observed, shown in Figure 4. So, we affirmed that the prepared $\mathrm{MgO}$ nanoparticles did not have any impurity phases which means that pure $\mathrm{MgO}$ nanoparticles have been obtained by green extract-mediated synthesis.

The average crystallite size of $\mathrm{MgO}$ nanoparticles has been calculated where Debye-Scherrer's formula was employed, shown as follows:

$$
D=K \cdot \lambda / \beta \cdot \cos \theta,
$$

where $D$ is the crystallite size, $\lambda$ is the $\mathrm{X}$-ray wavelength for Cuk $\alpha$ radiation $\left(1.5406 \mathrm{~A}^{\circ}\right), \theta$ is Bragg's diffracting angle, $\beta$ is the full-width half maximum (FWHM) strain broadening, and $\mathrm{K}$ is the shapeless factor.
4.2. William-Hall Method and UDM (Uniform Deformation Model). The $\mathrm{W}-\mathrm{H}$ method had been used to find the microstrain of the nanopowder and crystallite size where the strain was considered to be uniform in all crystallographic directions which means consideration of the isotropic nature of crystals.

The lattice strain and crystallite size can be obtained from the following formalism:

$$
\beta \cdot \operatorname{Cos} \theta=(K \cdot \lambda / D)+(4 \varepsilon \sin )
$$

where $\varepsilon$ is the lattice strain, $D$ is the crystallite size, $\beta$ is the strain broadening, $k$ is the dimensionless shape factor (0.9), $\lambda$ is the $\mathrm{X}$-ray wavelength for $\operatorname{Cuk} \alpha$ radiation $\left(1.5406 \mathrm{~A}^{\circ}\right)$, and $\theta$ is Bragg's diffracting angle.

The graph was plotted between $\beta \cos \theta$ vs $4 \sin \theta$ at $Y$ - and $X$-axis, respectively, and fitted linearly. The lattice strain could be calculated from the slope (gradient), and crystallite

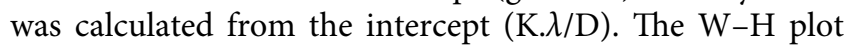
showed that there were positive and negative slopes (strain) due to the existence of compression and tensile strain on the lattice. The $\mathrm{W}-\mathrm{H}$ plot is shown in Figure 5. 


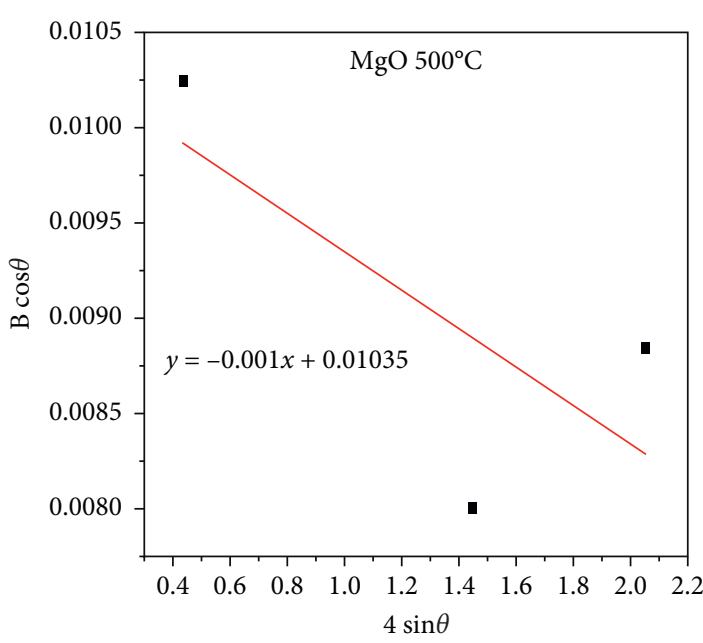

(a)

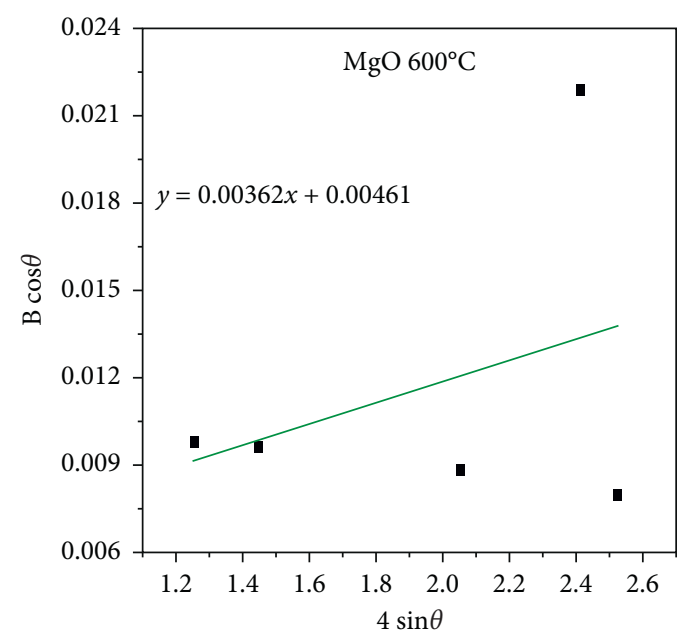

(b)

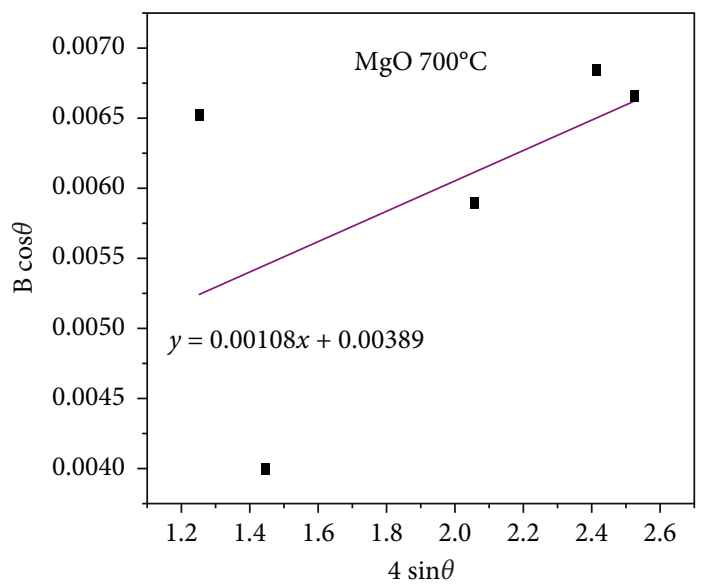

(c)

Figure 5: William-Hall plot of $\mathrm{MgO}$ nanoparticles at $500^{\circ} \mathrm{C}, 600^{\circ} \mathrm{C}$, and $700^{\circ} \mathrm{C}(\mathrm{a}, \mathrm{b}$, and c).

Table 1: Calculated crystallite size and lattice parameters, dislocation density, and lattice strain.

\begin{tabular}{|c|c|c|c|c|c|c|}
\hline \multirow[b]{2}{*}{$\begin{array}{l}\text { Temperature } \\
\left({ }^{\circ} \mathrm{C}\right)\end{array}$} & \multicolumn{2}{|c|}{ Average crystallite size (D) } & \multirow[b]{2}{*}{$\begin{array}{l}\text { Lattice } \\
\text { constant } \\
\left(\mathrm{A}^{\circ}\right)^{(\mathrm{a})}\end{array}$} & \multirow[b]{2}{*}{$\begin{array}{c}\text { Unit cell } \\
\text { volume }\left(\mathrm{A}^{\circ}\right)\end{array}$} & \multirow[b]{2}{*}{$\begin{array}{c}\text { Dislocation } \\
\text { density }\left(\delta \times 10^{-3}\right)\end{array}$} & \multirow[b]{2}{*}{ Lattice strain $\mathrm{W}-\mathrm{H}\left(\times 10^{-3}\right)(\mathrm{UDM}$ model $)$} \\
\hline & $\begin{array}{c}\text { Debye } \\
\text { method } \\
(\mathrm{nm})\end{array}$ & $\begin{array}{l}\text { W-H } \\
\text { method } \\
(\mathrm{nm})\end{array}$ & & & & \\
\hline 500 & 14 & 13 & 4.246 & 77 & 2.704 & -1 \\
\hline 600 & 10 & 30 & 4.247 & 76 & 9.772 & 3.62 \\
\hline 700 & 19 & 35 & 4.257 & 77 & 5.173 & 1.08 \\
\hline
\end{tabular}

The lattice constant $(a)$ and volume of the unit cell $(V)$, and dislocation density of $\mathrm{MgO}$ nanoparticles have been found using the following formulae [46, 47]:

$$
a=\sqrt{h^{2}}+K 2+l^{2} \times d^{2},
$$

where $d$ is the interplanar spacing and $h, k$, and $l$ are the miller indices,

$$
V=\frac{1}{(a)^{3}}
$$

where $a$ is the lattice constant,

$$
\delta=1 / D^{2}
$$

where $D$ is the crystallite size.

The crystallite size was calculated from Debye-Scherrer's method and the $\mathrm{W}-\mathrm{H}$ plot method.

The calculated crystallite size and lattice parameters, dislocation density, and lattice strain are shown in Table 1.

Debye's method and $\mathrm{W}-\mathrm{H}$ method. Crystallite size was found to an increasing trend while increasing temperature. The crystallite size was found by both methods which are not in the same size but the same increasing trend of in size while 


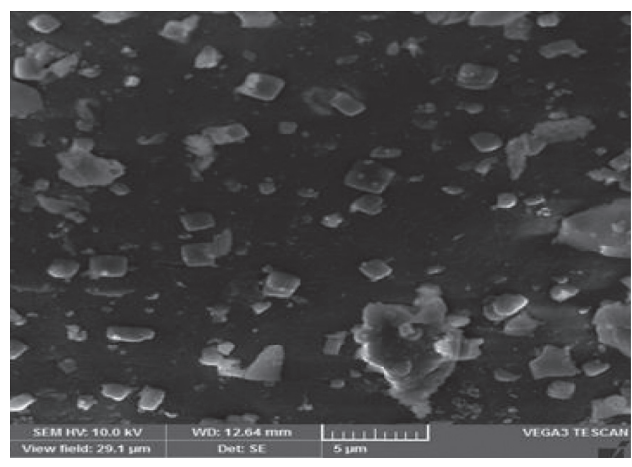

(a)

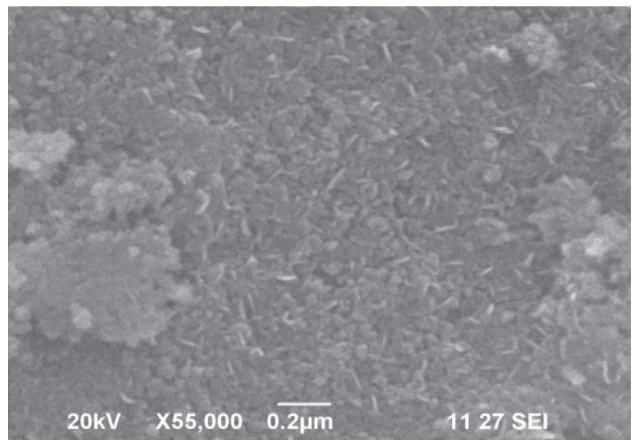

(c)

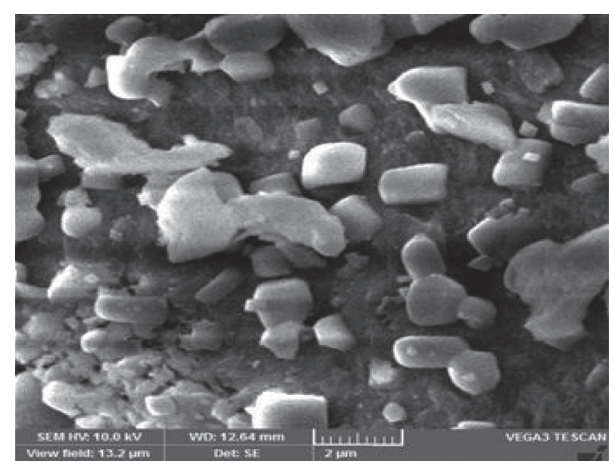

(b)

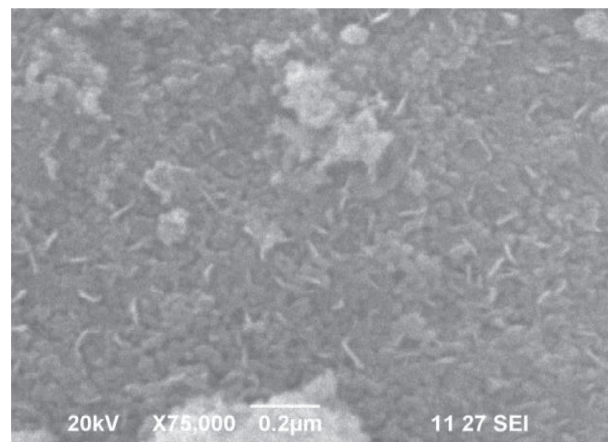

(d)

Figure 6: SEM images of $\mathrm{MgO}$ nanoparticles at $500^{\circ} \mathrm{C}$ (a), $600^{\circ} \mathrm{C}(\mathrm{b})$, and $700^{\circ} \mathrm{C}(\mathrm{c}, \mathrm{d})$.

temperature increases. The lattice constant has also increased with temperature, but unit cell volume was found to decrease. The lattice strain found by the $\mathrm{W}-\mathrm{H}$ method having positive and negative slope values due to having tensile and compress stress and in deeply the negative slope value of strain implicitly meant that there was no strain with $500^{\circ} \mathrm{C}$ calculations [45]. The unit cell volume decreases with increasing calcination temperature. Dislocation density is high while calcination with $600^{\circ} \mathrm{C}$ with strain. All the values are shown in Table 1.

\subsection{Morphological Surface Analysis}

4.3.1. Scanning Electron Microscope (SEM) Imaging Techniques. The calcined $\mathrm{MgO}$ nanopowder morphology was exhibited in low-resolution SEM micrographs which are shown in Figure 6. Calcination-dependent morphology transformation was obtained. The $\mathrm{MgO}$ nanopowder has distinct morphology during each stage of calcination temperature which is exhibited in micrographs. The $\mathrm{MgO}$ nanopowder was calcined at $500^{\circ} \mathrm{C}$, and the cubic in shape morphology was observed whereas at $600^{\circ} \mathrm{C}$ and $700^{\circ} \mathrm{C}$ nanobar, hexagonal in shape morphology has been observed. Figures 6(a) and 6(d) illustrate cubic, nanobar, and hexagonal morphology. All the shapes were irregular, clustered, and aggregated, and shapes were dependent on calcination. Shape transformation was attained by the influence of temperature, and size was enlarged during the increase of temperature and modified the shapes.

\subsubsection{High-Resolution Transmission Electron Microscope} Imaging Analysis (HR-TEM). To study particle size, morphology, and nature of particles, HR-TEM analysis was employed and the crystalline nature of materials was studied by SAED (selected area electron diffraction) pattern. $\mathrm{MgO}$ nanopowder was dispersed in ethanol on a carbon-coated copper grid, and taken HR-TEM micrographs are shown in Figures 7(a), 7(b), 7(d), 7(e), 7(g), and 7(h). The micrographs of HR-TEM illustrated that $\mathrm{MgO}$ nanoparticles were aggregated and morphological transformation was observed owing to influences of temperature. The nanoparticles were nano in size (1-100 $\mathrm{nm}$ ) range, and particle size was matched with XRD crystallite size. The SAED (selected area electron diffraction) patterns of $\mathrm{MgO}$ nanoparticles are shown in Figures 7(c), 7(f), and 7(i). Here, we have observed that in all the three calcination temperatures, there were distinct multiple rings with discrete tiny bright spots which are make up the ring which could be implied the nanoparticle were polycrystalline in nature and nano in size. The bright field of HR-TEM images was clearly illustrated, and the nanoparticles were cubic in shape at $500^{\circ} \mathrm{C}$, nanobar at $600^{\circ} \mathrm{C}$, hexagonal in shape at $700^{\circ} \mathrm{C}$. The $\mathrm{d}$-spacing found by the SAED pattern is matched with the XRD report. To reduce the total surface energy of the system, the nanoparticles were got aggregated. HR-TEM images and SAED patterns of $\mathrm{MgO}$ nanoparticles at $500^{\circ} \mathrm{C}(\mathrm{a}, \mathrm{b}, \mathrm{c}), 600^{\circ} \mathrm{C}(\mathrm{d}, \mathrm{e}, \mathrm{f})$, and $700^{\circ} \mathrm{C}(\mathrm{g}$, $h, i)$ were clearly illustrated in the micrographs.

4.3.3. Elemental Composition Analysis-Energy Dispersive $X$-ray Spectroscopy (EDX). The chemical concentration of $\mathrm{MgO}$ nanoparticles could be estimated by the energy dispersive X-ray spectroscopy (EDX) characterization 


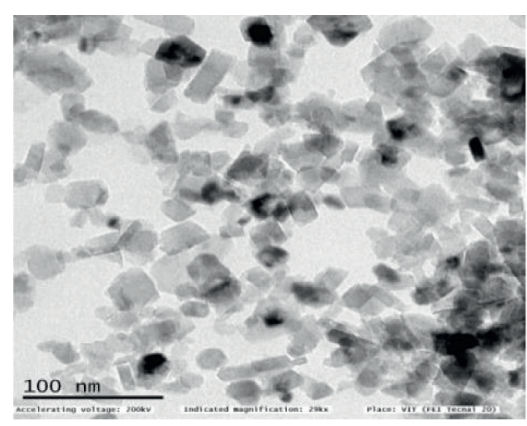

(a)

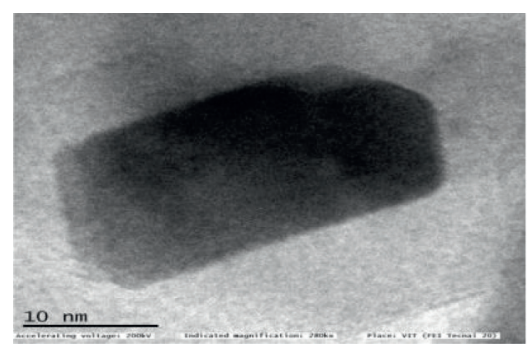

(d)

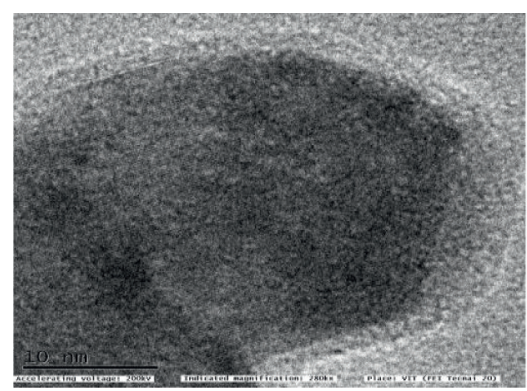

(g)

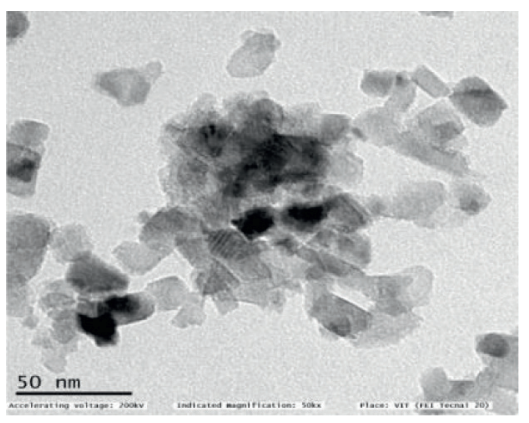

(b)

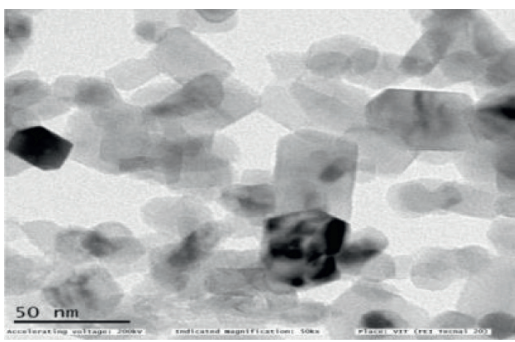

(e)

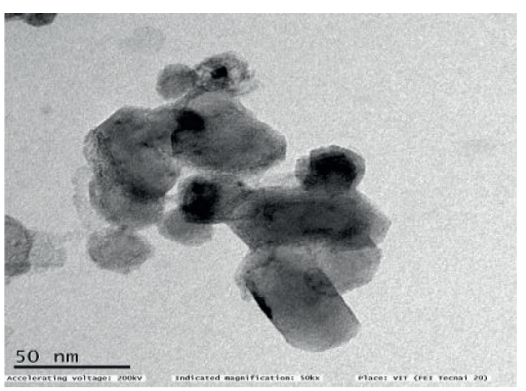

(h)

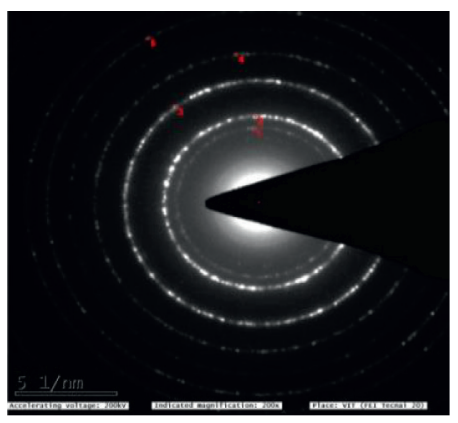

(c)

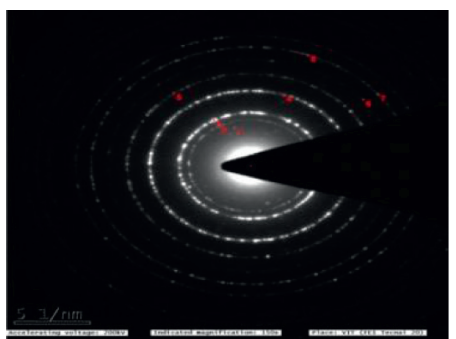

(f)

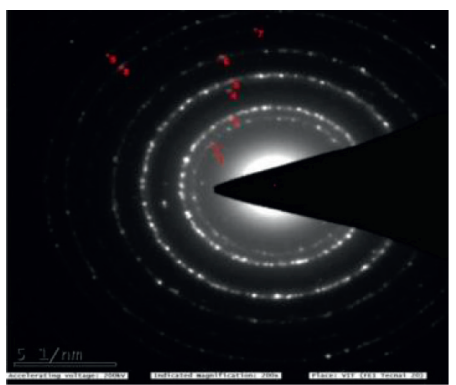

(i)

Figure 7: HR-TEM images and SAED patterns of $\mathrm{MgO}$ nanoparticles at $500^{\circ} \mathrm{C}(\mathrm{a}-\mathrm{c}), 600^{\circ} \mathrm{C}(\mathrm{d}-\mathrm{f})$, and $700^{\circ} \mathrm{C}(\mathrm{g}-\mathrm{i})$.

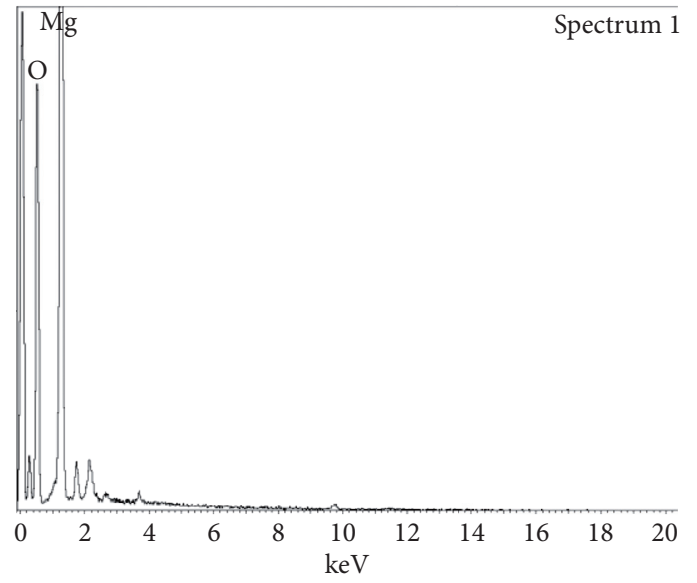

(a)

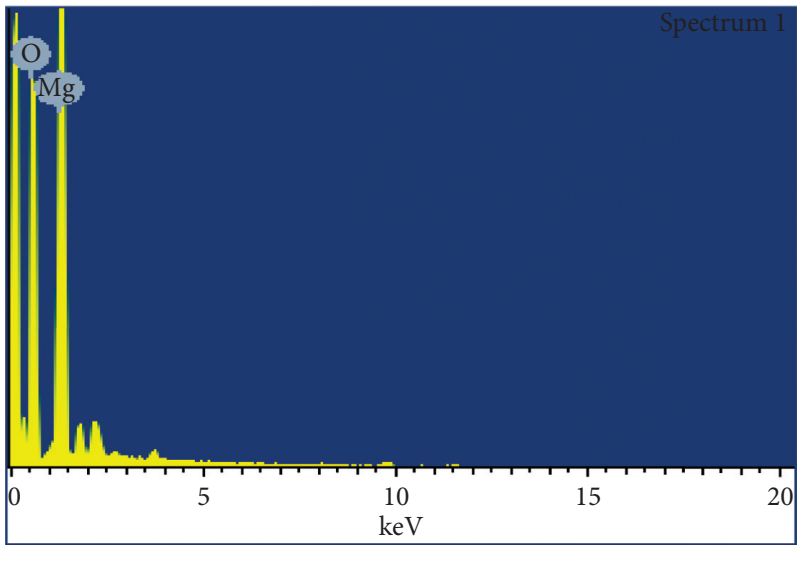

(b)

$\begin{array}{lrrrrr}\text { Element } & \begin{array}{c}\text { App } \\ \text { conc. }\end{array} & \begin{array}{c}\text { Intensity } \\ \text { conc. }\end{array} & \text { Weight\% } & \begin{array}{c}\text { Weight\% } \\ \text { sigma }\end{array} & \text { Atomic\% } \\ \text { OK } & 114.53 & 1.4671 & 50.21 & 0.52 & 60.52 \\ \text { Mg K } & 67.85 & 0.8766 & 49.79 & 0.52 & 39.48 \\ \text { Totals } & & & 100.00 & & \end{array}$




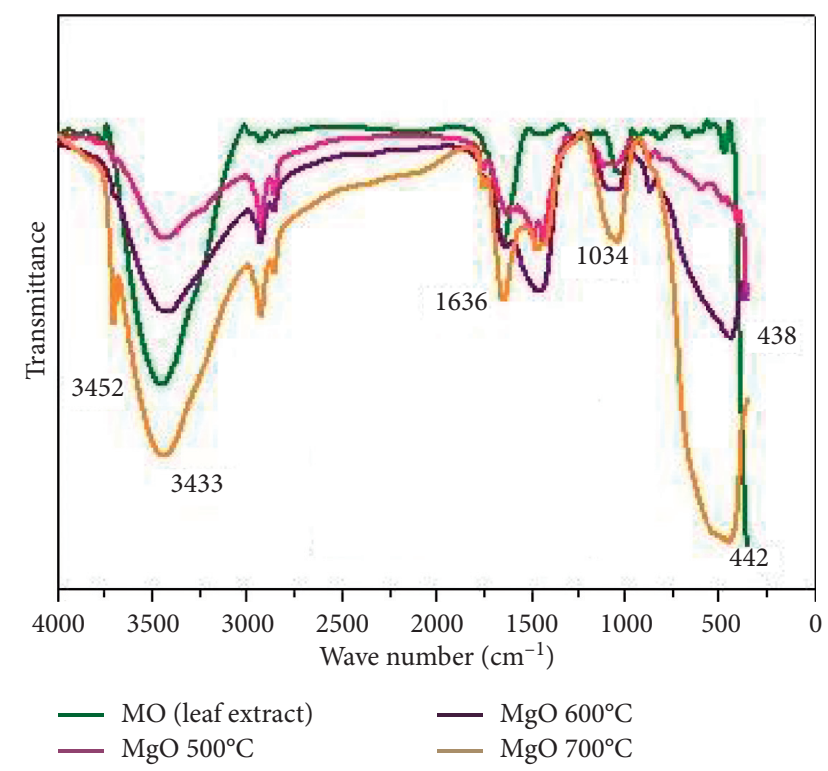

FIgURE 9: FTIR spectra of calcined $\mathrm{MgO}$ nanoparticles and Moringa oleifera leaf extract.

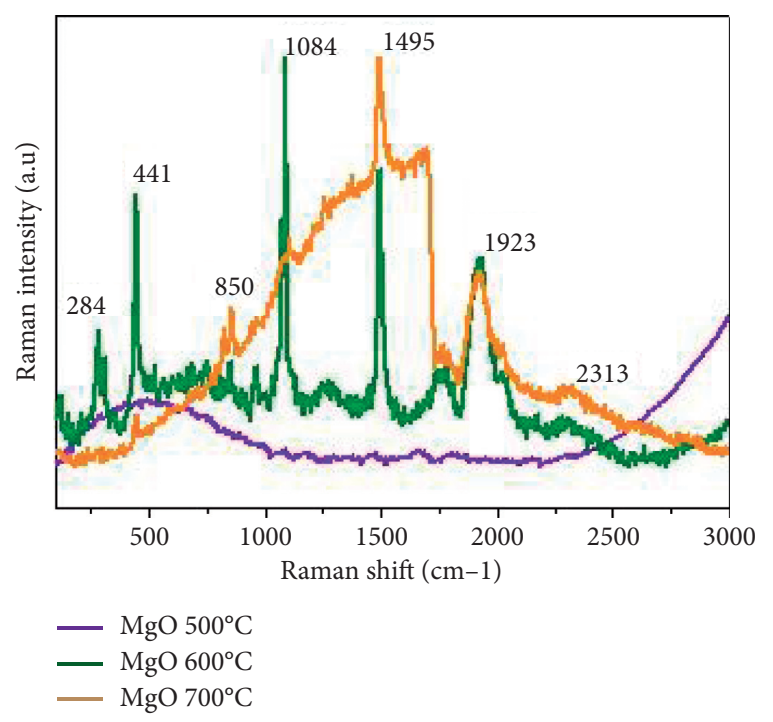

Figure 10: Micro-Raman spectra of MgO nanoparticles.

technique with fresh dispersion of nanopowder. Energy dispersive X-ray spectroscopy (EDX) spectrum is shown in Figures 8(a) and 8(b). The spectrum consists of $\mathrm{Mg}$ and $\mathrm{O}$ element only, and there was no evidence of impurities along with $\mathrm{Mg}$ and $\mathrm{O}$. The atomic percentage of $\mathrm{Mg}$ and $\mathrm{O}$ was indicted in the energy dispersive X-ray spectroscopy (EDX) spectra table (shown in Figure 8(c) and we observed that it has a good stoichiometric ratio of $\mathrm{Mg}$ and $\mathrm{O}$.

\subsection{Vibrational Characterization}

4.4.1. FTIR (Fourier Transform Infrared) Analysis. The phytochemicals were confirmed by functional group analysis which has an important role in the formation of nanoparticles which were acted as stabilizing and capping agents [48]. The functional groups which were absorbed on the surface have been identified with FTIR characterization. FTIR spectra were recorded in the range of $400-4000 \mathrm{~cm}^{-1}$ as shown in Figure 9. Aqueous extract of Moringa oleifera leaf FTIR spectra had four intense peaks, among them, $3433 \mathrm{~cm}^{-1}$ and $3452 \mathrm{~cm}^{-1}$ bands attributed to $-\mathrm{OH}$ stretching vibrations owing to the presence of ester, alcohol, carboxylic acid, and ether groups, and peak $1636 \mathrm{~cm}^{-1}$ assigned to $-\mathrm{OH}$ bending vibration [49]. The band belongs to $1034 \mathrm{~cm}^{-1}$ is aromatic stretching bands of various bioactive compounds and proteins. The band at $1034 \mathrm{~cm}^{-1}$ corresponds to the aromatic stretching of various bioactive compounds and proteins. The transformation occurred from enol form to keto form due to the presence of flavonoids and phenols. This mechanism reduces the metal ions and forms nanoparticles since it releases reactive $\mathrm{H}$ atoms and forms the $\mathrm{O}-\mathrm{H}$ group since the phenol group has electron-donating ability [48]. The metal oxide characteristic absorption band arises below $1000 \mathrm{~cm}^{-1}$ to form interatomic vibrations. Biosynthesized $\mathrm{MgO}$ particle characteristic band exhibited at $442 \mathrm{~cm}^{-1}$ and $438 \mathrm{~cm}^{-1}$ which are assigned to the stretching mode of $\mathrm{MgO}$ [50-52].

4.4.2. Micro-Raman Scattering. Raman spectroscopy is the vibrational technique used to identify crystal structural information, differentiate the multiple phases in metal oxides, changes in metal-oxygen bond, bond lengths, metal oxidation state, lattice disorder, and distortions, and study the intramolecular and lattice vibrations [53]. Raman spectrum of the cubic phase of periclase with the $\mathrm{Fm} 3 \mathrm{~m}$ space group has not been identified much in the literature. Limited papers have done the Raman investigation for this cubic phase of $\mathrm{MgO}$ NPs. Raman spectra recorded for $\mathrm{MgO}$ in the range of $100 \mathrm{~cm}^{-1}$ to $3000 \mathrm{~cm}^{-1}$ are given in Figure 10. MgO NPs possess a high-ordered lattice $\mathrm{NaCl}$ structure with cubic space group $\mathrm{O}^{5 \mathrm{~h}}$ with cubic structure $(\mathrm{Fm} 3 \mathrm{~m})$ symmetry. The vibration modes of $\mathrm{MgO}$ nanoparticles which are expected have been written by group theory analysis. It has four Raman active modes and one IR active mode:

$$
\begin{aligned}
\Gamma_{\mathrm{opt}}= & \mathrm{A} 1 \mathrm{~g}(\mathrm{R})+\mathrm{Eg}(\mathrm{R})+\mathrm{F} 1 g(\text { silent })+2 \mathrm{Fg}(\mathrm{R}) \\
& +4 \mathrm{~F} 1 \mathrm{u}(\mathrm{IR})+\mathrm{F} 2 \mathrm{u}(\text { silent })
\end{aligned}
$$

where $4 \mathrm{~F} 1 \mathrm{u}$ is the infrared active modes and $\mathrm{A} 1 \mathrm{~g}+\mathrm{Eg}+2 \mathrm{Fg}$ are the Raman active modes $[54,55]$. The room temperature Raman spectra recorded for $\mathrm{MgO}$ nanoparticles in the range of $100 \mathrm{~cm}^{-1}$ to $3000 \mathrm{~cm}^{-1}$ are exhibited in Figure 10 . $\mathrm{MgO}$ nanoparticles have Raman active vibrational mode with major Raman band $447 \mathrm{~cm}^{-1}, 850 \mathrm{~cm}^{-1}, 1084 \mathrm{~cm}^{-1}$, $1495 \mathrm{~cm}^{-1}, 1923 \mathrm{~cm}^{-1}$, and $2322 \mathrm{~cm}^{-1}$. There are no vibrational bands which have been observed at cubic morphology at $500^{\circ} \mathrm{C}$. Raman vibrations are observed only when increasing the calcination temperature to $600^{\circ}$ and $700^{\circ} \mathrm{C}$, and the intensity of the peak increases and the spectra show the characteristic peak of $\mathrm{MgO}$ at $447 \mathrm{~cm}^{-1}$, 


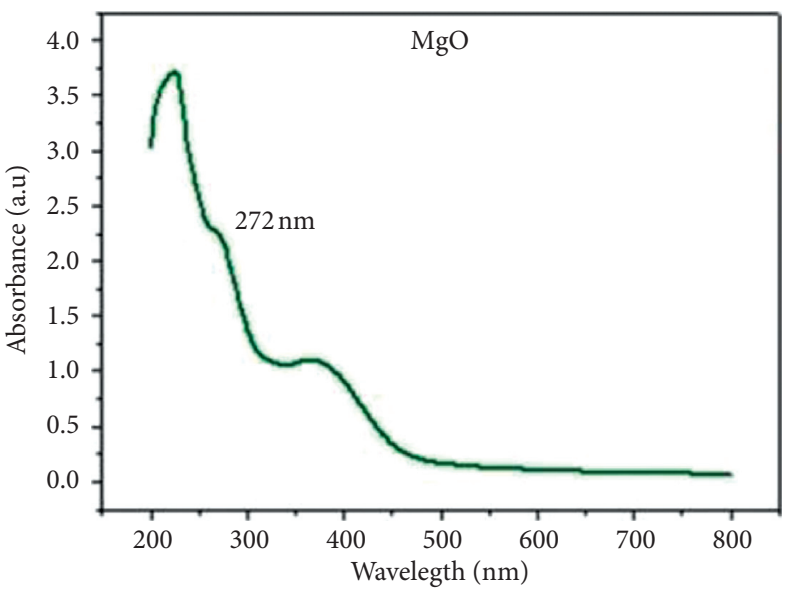

(a)

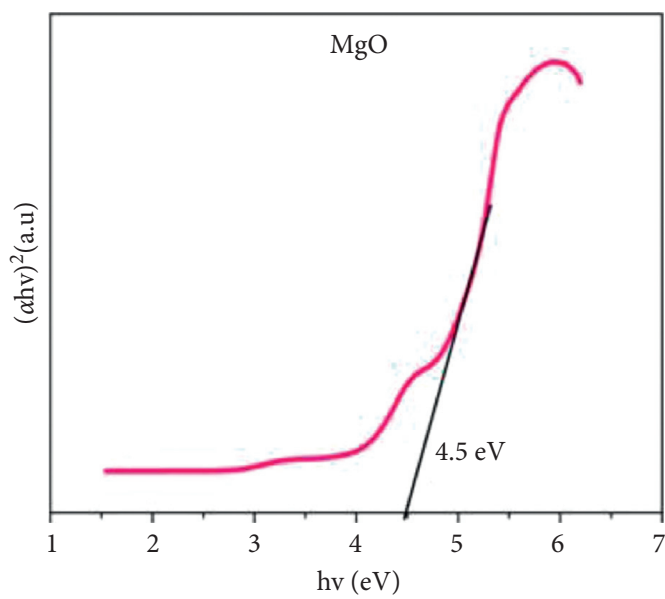

(b)

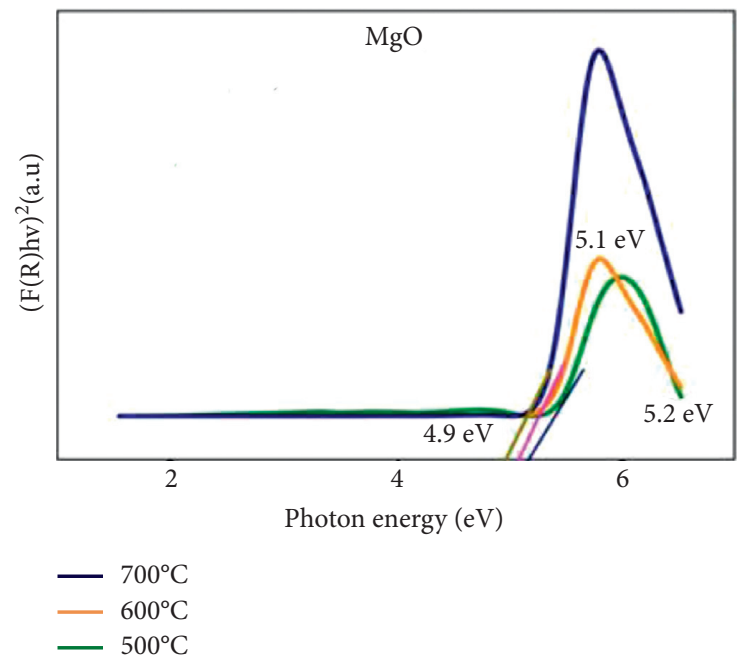

(c)

FIGURE 11: Energy dispersive X-ray spectroscopy (EDX) spectra of $\mathrm{MgO}$ nanoparticle (a, b) and atomic percentage of Mg and O (c).

$850 \mathrm{~cm}^{-1}$, and $2322 \mathrm{~cm}^{-1}[54,56]$. The Raman bands are observed in the range of $200-600 \mathrm{~cm}^{-1}$ for metal oxide minerals [57]. The band belongs to $1084 \mathrm{~cm}^{-1}$ appears owing to TO-LO surface phonon modes, and G-band and $\mathrm{D}$-band peaks were observed. The peaks observed below $1500 \mathrm{~cm}^{-1}$ were attributed to D-band and above $1500 \mathrm{~cm}^{-1}$ were assigned a to G-band [58]. The peaks found under the $300 \mathrm{~cm}^{-1}$ are attributed to lattice modes. The twisting and stretching modes are found in the midfrequency region. The peaks are found at 579,719 , and $1096 \mathrm{~cm}^{-1}$ since the $\mathrm{MgO}$ particle has a size between 10 and $30 \mathrm{~nm}$ [54]. The IR active mode was observed at $850 \mathrm{~cm}^{-1}$ due to contributions coming from $\mathrm{F} 1$ (angle bond $\mathrm{O}-\mathrm{Mg}-\mathrm{O}$, stretching bond $\mathrm{O}-\mathrm{O})$. It describes the octahedral breathing-type vibrations [55]. The F1u IR active mode observed at $850 \mathrm{~cm}^{-1}$ occurs on the repulsive force between $\mathrm{O}-\mathrm{O}$ and bending force $\mathrm{O}-\mathrm{Mg}-\mathrm{O}$ for angle bond [54]. The band at $1084 \mathrm{~cm}^{-1}$ corresponds to TO-LO surface phonon modes. The peaks appear below $1500 \mathrm{~cm}^{-1}$ attributed to D-band is known as breathing mode, and the peaks above $1923 \mathrm{~cm}^{-1}$ and $2322 \mathrm{~cm}^{-1}$ are assigned to G-band [59]. The ratio between
D-band and G-band gives the information about crystallite size and surface defects, and the peaks with strong intensities indicate the cubic structure [59].

\subsection{Optical Property Analysis}

4.5.1. UV-Visible Absorption Spectroscopy Characterization (before Calcination-as Prepared). UV-Vis absorbance spectroscopy has revealed the optical property and electronic structure of nanoparticles. The absorbance spectrum was recorded in the range of $200 \mathrm{~nm}$ to $800 \mathrm{~nm}$. The UV-visible absorption spectrum of MgO NPs is shown in Figures 11(a) and 11(b). The absorption band edge was found at $273 \mathrm{~nm}$ $(4.5 \mathrm{eV})$. The absorbance of $\mathrm{MgO}$ nanoparticles at the $\mathrm{UV}$ region was $273 \mathrm{~nm}$ due to surface plasmon resonance. The $\mathrm{UV}$ region absorption band at $273 \mathrm{~nm}(4.5 \mathrm{eV})$ is found with the excitation of 3 -fold coordinated $\mathrm{O}^{2-}$ anions in the edges and corners and defects on the surface ( $\mathrm{F}$ centers), respectively $[51,60,61]$. The energy band gap ( $\mathrm{Eg})$ could be found from Tauc plot, and the formula employed is given as follows: 


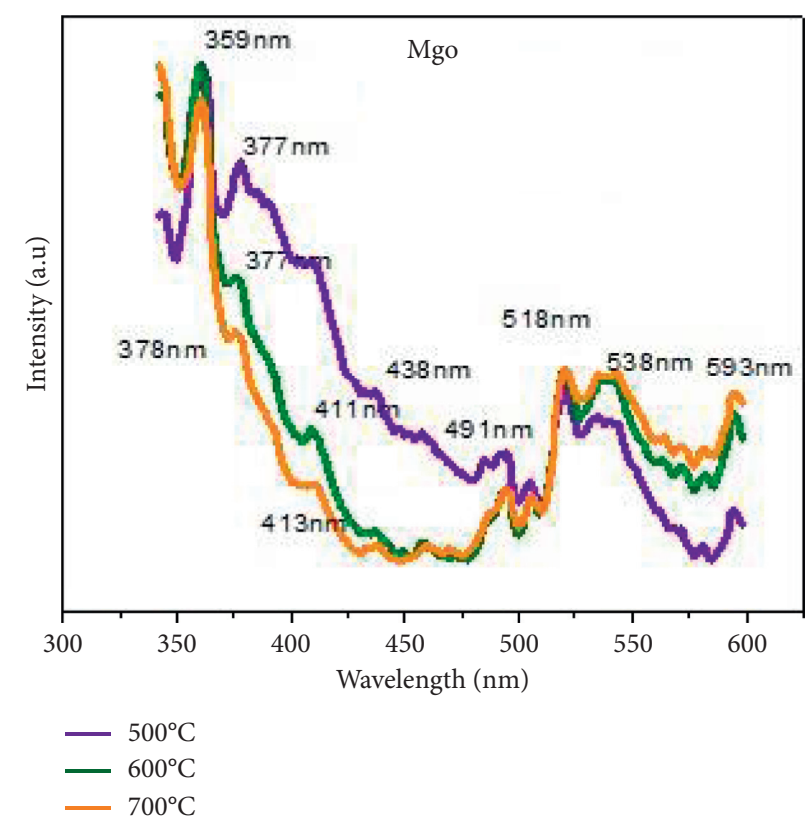

Figure 12: Photoluminescence emission spectra of $\mathrm{MgO}$ nanoparticles (a).

$$
\alpha=A(h \sqrt{ }-E g)^{n} / h \sqrt{ }
$$

where $\alpha$ is the absorption coefficient, $E g$ is the absorption band gap, $A$ is a constant, $h \sqrt{ }$ is the energy of the photon, and $n$ is the nature of transitions. The band gap value could be determined from the intercept of the straight line with the $h \sqrt{ }$. The Tauc plot is shown in Figure 11(b). The computed optical band gap value $4.5 \mathrm{eV}$ was considered as a lower band gap of the MgO NPs due to the presence of 3coordinated surface anions at the corners whereas the bulk $\mathrm{MgO}$ material has band gap of $7.8 \mathrm{eV}$ owing to the existence of 6-coordinated surface anions. The computed band gap value of $\mathrm{MgO}$ NPs well matches with previous reports [62-67].

4.5.2. UV-Vis Spectroscopy in Reflectance Mode (after Calcination). The optical properties of MgO NPs after calcination have been studied from the reflectance spectrum, and also it was recorded in the range of $200 \mathrm{~nm}$ to $800 \mathrm{~nm}$ in reflectance mode where diffuse reflectance spectrometer was employed. The optical band gap energy of MgO NPs at different calcination temperatures was calculated by Kubelka-Munk function:

$$
F(R)=(1-R)^{2} / 2 R,
$$

where $R$ is the reflectance. The graph has been plotted between $(F(R) \mathrm{h} v)^{2}$ and $\mathrm{h} \nu$. The energy band gap value at different calcination temperatures has been calculated by extrapolation of the linear part of the $(F(R) h \nu)^{2}$ at the $X$-axis plot to the intersection with $\mathrm{h} \nu$ at $Y$-axis. The energy band gap value computed is $5.2 \mathrm{eV}, 5.1 \mathrm{eV}$, and $4.9 \mathrm{eV}$ for $500^{\circ}$, $600^{\circ}$, and $700^{\circ} \mathrm{C}$ which is illustrated in Figure $11(\mathrm{c})$. The band gap value has been decreased with increasing temperature which was observed owing to the growth of particles and crystallinity and the value is well-matched with previous reports, and the smallest band gap was observed when calcined at $700^{\circ} \mathrm{C}[68-71]$.

\subsection{Photoluminescence Spectroscopy Analysis}

4.6.1. Room Temperature Emission Spectroscopy. The PL spectrum of $\mathrm{MgO}$ nanoparticles was recorded at room temperature with a Xe lamp as an excitation light source at excitation wavelength $320 \mathrm{~nm}$. Photoluminescence emission spectra are depicted in Figure 12. Holes from the valence band and electrons from the electronic states recombine with each other, and this is responsible for the emission behavior of transition metals. The recombination of photoexcited electron and hole pairs at the energy states would induce the photoemission. The nature of the defects causes light emission. Photoluminescence gives the information about the impurities and defects in nanoparticles [61, 72]. The defect centers create different electronic states in the wide band gap of the material such as such $\mathrm{F}$ - and $\mathrm{F}_{2}$-type centers $\left(\mathrm{F}, \mathrm{F}^{+}, \mathrm{F}_{2}{ }^{1+}, \mathrm{F}_{2}^{2+}\right.$, and $\left.\mathrm{F}_{2}^{3+}\right)$, cationic vacancies $\left(\mathrm{V}_{\mathrm{Mg}}{ }^{-2}\right)$, Schottky defect $\left(\mathrm{V}_{\mathrm{Mg}}^{0}+\mathrm{V}^{0}\right)$, and interstitial oxygen atom $\left(\mathrm{O}_{i}^{0}, \mathrm{O}_{i}^{-1}\right.$, and $\left.\mathrm{O}_{i}^{-2}\right)$, and those are responsible for multicolor emission [73]. The emission spectrum shows emission at different wavelengths due to different color centers on the $\mathrm{MgO}$ nanoparticles shown in Tables 2 and 3. The emission spectrum shows emission at different wavelengths due to different color centers on the $\mathrm{MgO}$ nanoparticles. It has arisen at UV-visible region. UV $(359 \mathrm{~nm})$, violet $(377 \mathrm{~nm}$, $378 \mathrm{~nm})$, blue $(491 \mathrm{~nm})$, green $(518)$, and orange $(593 \mathrm{~nm})$ emissions were found in PL spectra. Luminescence of $\mathrm{MgO}$ nanoparticles arises at UV region $(359 \mathrm{~nm})$ due to oxygen vacancies (surface defects). If defect is high, intensity will also be high. Green emission has aroused due to F centers. 


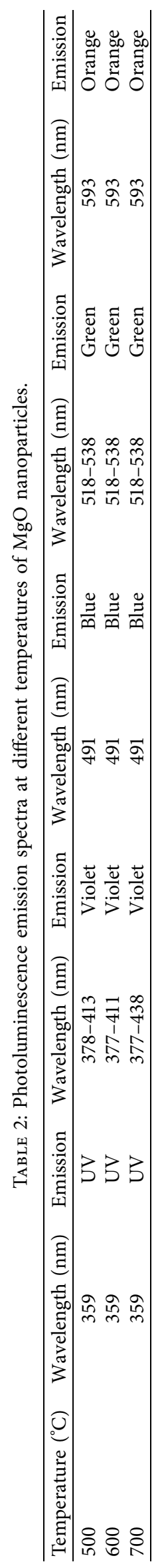


TABLE 3: Photoluminescence emission spectra at different temperatures of $\mathrm{MgO}$ nanoparticles.

\begin{tabular}{|c|c|c|c|c|c|}
\hline $\begin{array}{l}\text { Metal oxide } \\
\text { NPs }\end{array}$ & $\begin{array}{l}\text { Peak position wavelength } \\
\text { (observed in } \mathrm{nm} \text { ) }\end{array}$ & Emission & $\begin{array}{l}\text { Energy } \\
(\mathrm{eV})\end{array}$ & Attribution & References \\
\hline \multirow{8}{*}{$\begin{array}{l}\mathrm{MgO} \\
\text { nanoparticles }\end{array}$} & 359 & UV & 3.45 & Surface defects & {$[31,74]$} \\
\hline & 378 & \multirow{4}{*}{ Violet } & 3.2 & & \multirow{4}{*}[31,33,54,55,75]{} \\
\hline & 411 & & 3.01 & Defect band transition. $\mathrm{F}^{+}\left(\right.$or $\left.\mathrm{V}_{\circ}^{+1}\right)$ & \\
\hline & 413 & & 3 & centers & \\
\hline & 438 & & 2.83 & & \\
\hline & 491 & Blue & 2.52 & $\begin{array}{c}\text { Recombination of electrons with oxygen } \\
\text { vacancies }\end{array}$ & {$[31,33,34,75]$} \\
\hline & $\begin{array}{l}518 \\
538\end{array}$ & $\begin{array}{l}\text { Green } \\
\text { Green }\end{array}$ & $\begin{array}{l}2.39 \\
2.30\end{array}$ & Oxygen vacancies $\left(\mathrm{V}_{\mathrm{o}}\right)$ & {$[31,33,48,52,53,74,76]$} \\
\hline & 593 & Orange & 2 & $\begin{array}{l}\text { Relaxation luminescence of defect centers } \\
\qquad \mathrm{F} 2^{1+} \text { created by mechanical stress }\end{array}$ & {$[31,48,52,53,74,76]$} \\
\hline
\end{tabular}

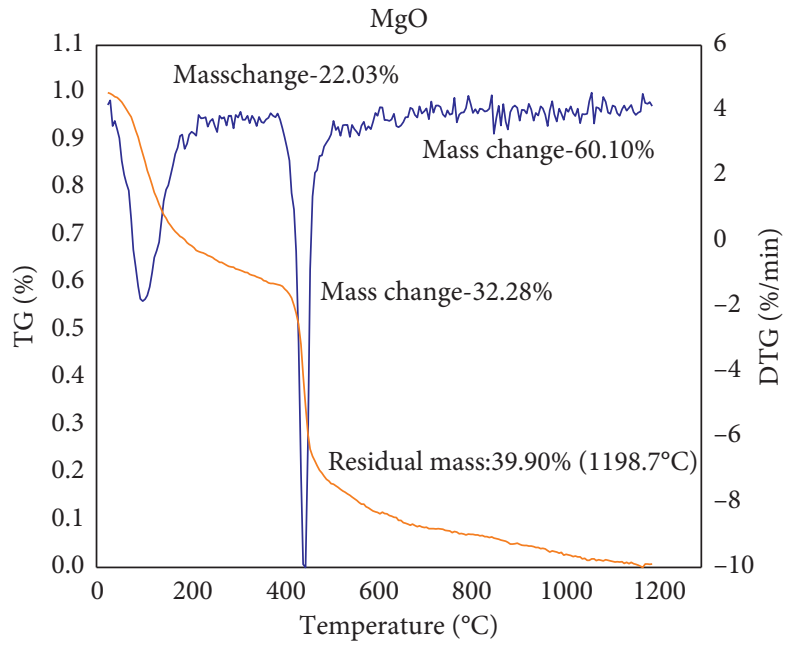

(a)

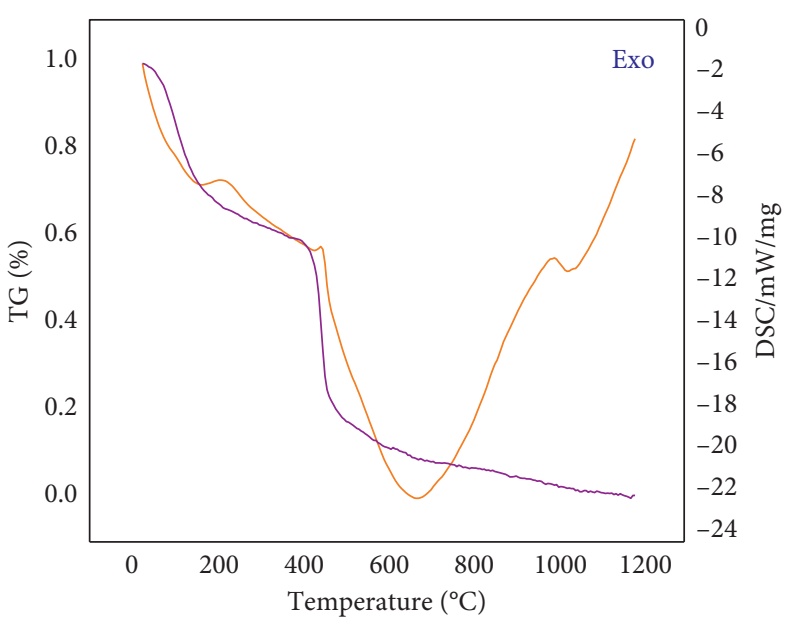

(b)

Figure 13: TGA DTA of MgO nanoparticles and TG-DSC of MgO nanoparticles (a, b).

The green emission arises around $518 \mathrm{~nm}$ due to oxygen vacancies that is excitation of $\mathrm{F}\left(\mathrm{V}_{\circ}^{0}\right)$ centers $[9,10,11]$. Red orange emission arises due to relaxation luminescence of defect centers $\mathrm{F}_{2}^{1+}$ created by mechanical stress. The orange emission arises at $593 \mathrm{~nm}$ due to relaxation luminescence of defect centers $\mathrm{F}_{2}^{1+}\left(\right.$ or $\left.\mathrm{V}_{\circ}^{+1}+\mathrm{V}_{\circ}^{0}\right)$ created by mechanical stress [9-11]. Violet emission arises due to $\mathrm{F}^{+}$centers. The violet emissions arise due to $\mathrm{F}^{+}\left(\right.$or $\left.\mathrm{V}_{0}^{+1}\right)$ centers. Blue emission was raised by hole trapped at $\mathrm{Mg}$ vacancy, and it was assigned to $\mathrm{F}_{2}$ center. The blue emission around $491 \mathrm{~nm}$ arises due to hole trapped at $\mathrm{Mg}$ ion vacancy, and it was assigned to $F_{2}$ center $[61,77,78]$. Multicolor emission observed in wide band gap of materials due to different electronic states there $[61,77,78]$. Multicolor emissions are observed in wide band gap materials due to different electronic states. PL optical study has given the physical property of the materials. So, according to the above study, $\mathrm{MgO}$ NPs will be used as potential material for optoelectronic applications.

\subsection{Thermal Analysis}

4.7.1. Thermogravimetric (TG), Differential Scanning Calorimetric (DSC), and Differential Thermal Analysis (DTA). The thermal decomposition behavior of samples as prepared was studied by TG and DSC thermographs. The change of weight of the sample concerning temperature measure is TGA. Changes in sample composition and thermal stability can be studied with weight loss of the sample. The TGA DTA and DSC thermographs of $\mathrm{MgO}$ nanoparticles are shown in Figures 13(a) and 13(b). The weight loss which occurs has been observed at 200- to 450-degree Celsius by exothermic peaks of DTA and DSC from the graph due to decomposition owing to absorption or removal $\mathrm{H}_{2} \mathrm{O}$ molecules and second weight loss due to the decomposition of bioactive compounds which is from the plant extract $[79,80]$. The DSC curve has one endothermic peak at $660^{\circ} \mathrm{C}$ where maximum weight loss occurs which implies phase transition of $\mathrm{Mg}(\mathrm{OH})_{2}$ to $\mathrm{MgO}$. Hence, the pure $\mathrm{MgO}$ nanoparticles have obtained with pure 


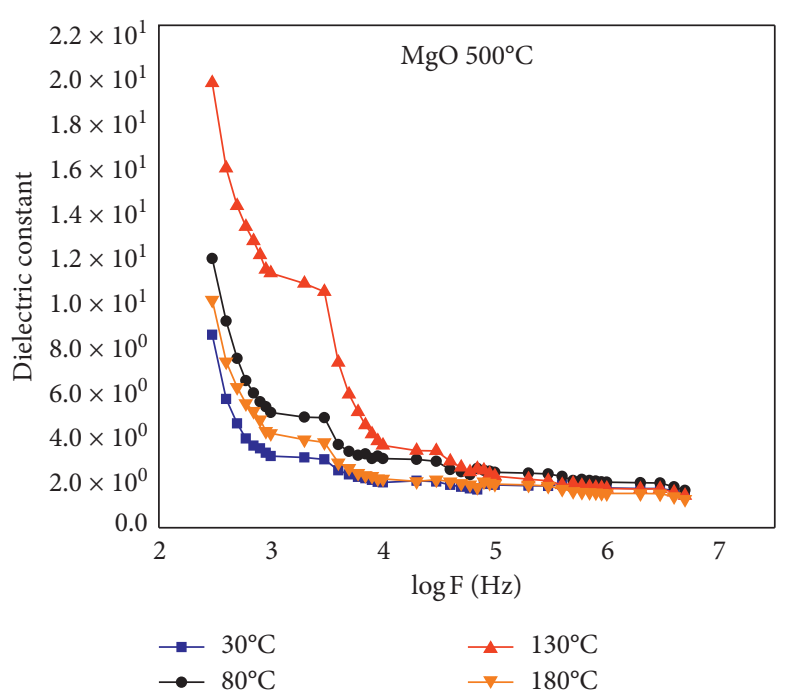

(a)

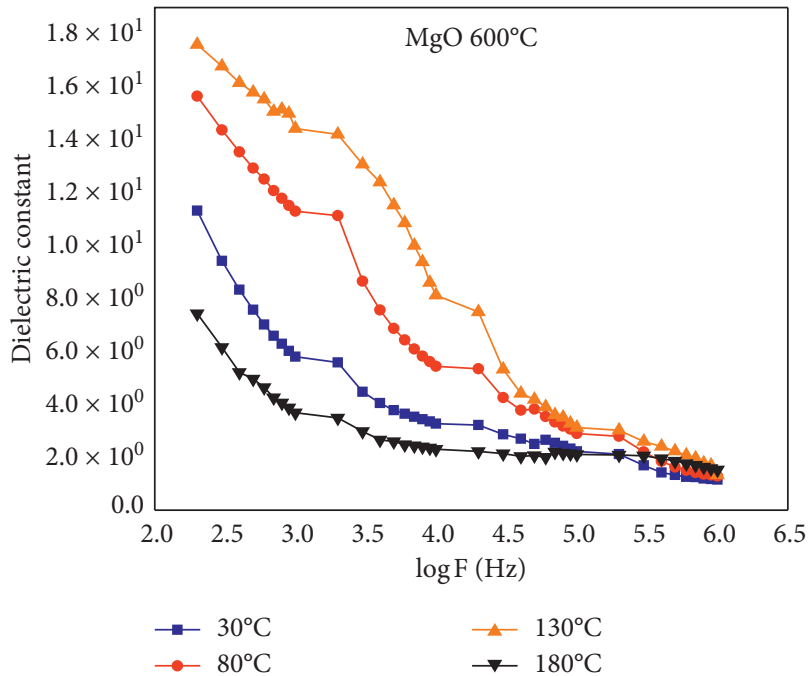

(b)

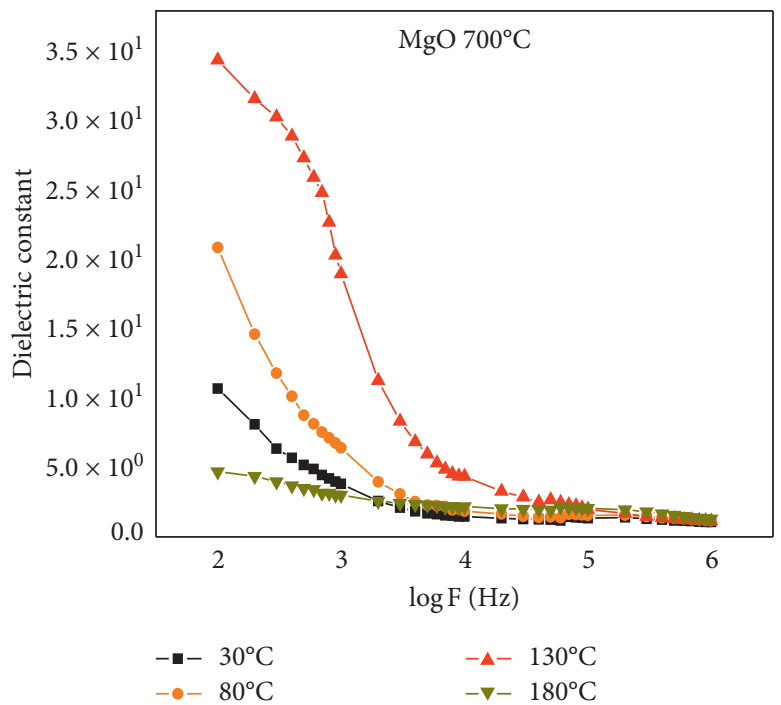

(c)

Figure 14: Dielectric constant of $\mathrm{MgO}$ nanoparticles at $500^{\circ} \mathrm{C}(\mathrm{a}), 600^{\circ} \mathrm{C}$ (b), and $700^{\circ} \mathrm{C}$ (c) with different temperatures.

phase at $700^{\circ} \mathrm{C}$ and the obtained results are well consistent with previous reports [79, 81-87].

\subsection{Electrical Properties}

4.8.1. Real Part of Dielectric Constant $\left(\varepsilon^{\prime}\right)$. The calcinated $\mathrm{MgO}$ nanopowder had pelletized by hydraulic pressure, and silver paste was coated on the surface to create better conduction. Frequency dependence of dielectric properties was studied with different temperatures from RT to $180^{\circ} \mathrm{C}\left(30^{\circ} \mathrm{C}\right.$, $80^{\circ} \mathrm{C}$, and $130^{\circ} \mathrm{C}$ and $180^{\circ} \mathrm{C}$ ). We design an energy storage device that needs to study the dielectric constant and dielectric breakdown strength which are the important parameters to calculate the energy density of the dielectrics. Dielectric loss is an important parameter for capacitor performance. The capacitance loss factor has been measured by the parallel plate capacitor method using an LCR meter for the frequency range between $100 \mathrm{~Hz}$ and $5 \mathrm{MHz}$ for different temperatures $\left(30^{\circ} \mathrm{C}\right.$, $80^{\circ} \mathrm{C}$, and $130^{\circ} \mathrm{C}$ and $180^{\circ} \mathrm{C}$ ).

The dielectric constant could be calculated by the relation (1) given as follows:

$$
\varepsilon_{r}=\mathrm{Cp} \times t / \varepsilon_{0} \times A,
$$

where $\varepsilon_{0}$ is the permittivity of the free space $(8.85 \times 10-12$ farad per meter $(\mathrm{F} / \mathrm{m}), \mathrm{Cp}$ is the capacitance in farad, $\mathrm{A}$ is an area of the cross section of pellet, and $t$ is the thickness of pellet.

The four type polarization namely space, charge, dipolar, ionic, electronic might be the reason for the dielectric nature of materials, and dielectric constant depends on these parameters. When frequency is applied from $100 \mathrm{~Hz}$ to $5 \mathrm{MHz}$, the 


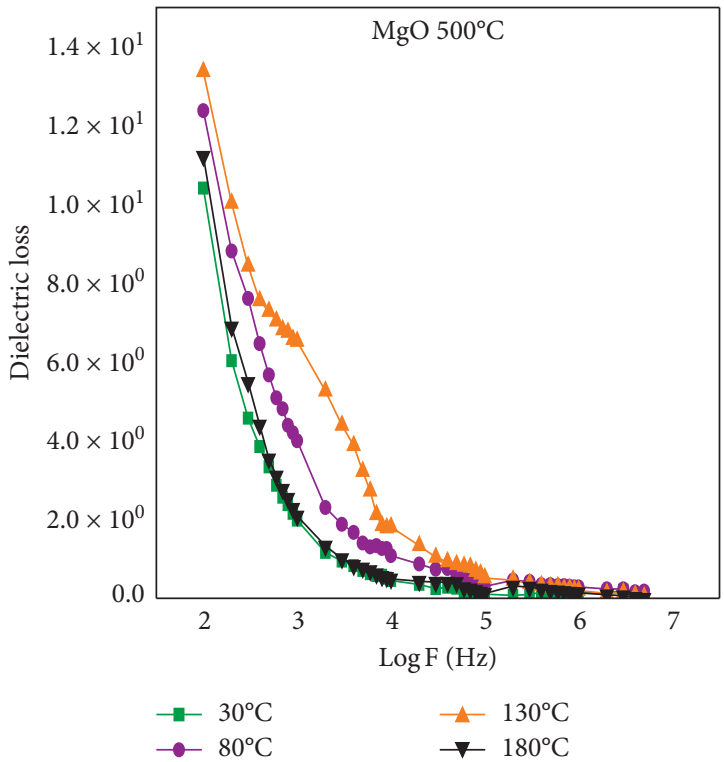

(a)

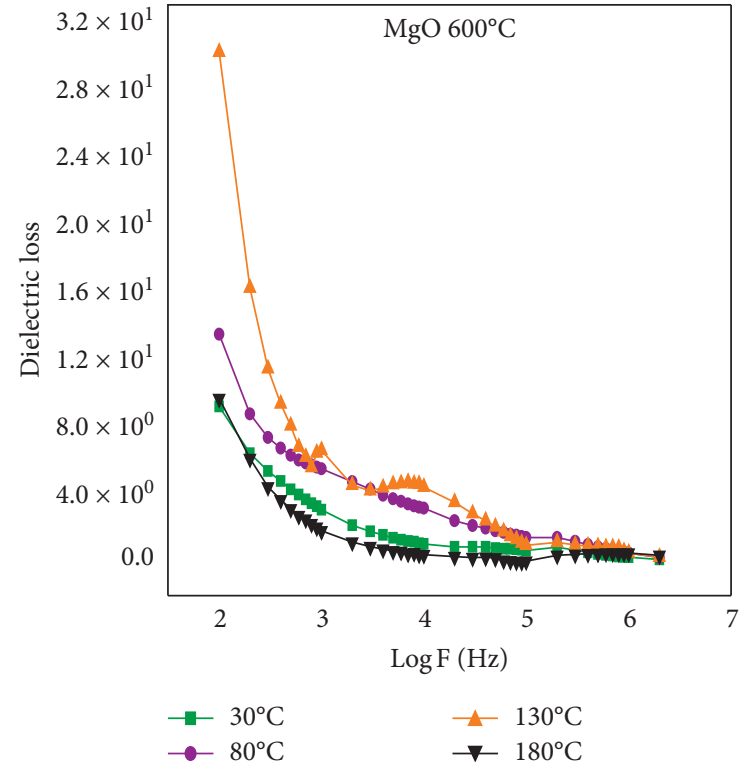

(b)

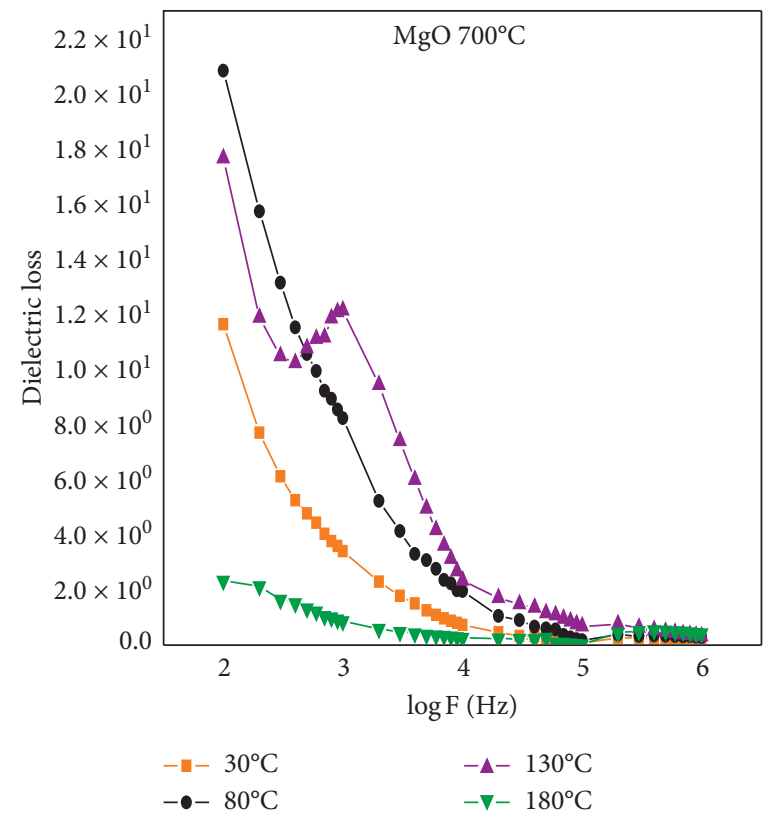

(c)

Figure 15: Dielectric loss of $\mathrm{MgO}$ nanoparticles at $500^{\circ} \mathrm{C}(\mathrm{a}), 600^{\circ} \mathrm{C}$ (b), and $700^{\circ} \mathrm{C}$ (c) with different temperatures.

Dielectric constant increases rapidly along with frequency which increases due to space charge polarization and interfacial polarization along with temperature increases from room temperature, as shown in Figures 14(a)-14(c). When applied frequency increases, the dielectric constant decreases its value gradually, and at the high-frequency range, its value is constant along with different temperatures; the same trend has happened, and it obeys Koop's theory owing to Maxwell-Wagner type interfacial polarization. At the high-frequency range, the same trend has followed at all the temperatures, the dielectric constant was found constant and merged due polarization decreases, and oxygen vacancies and grain boundaries were might be the reason for a large value of dielectric constant at lower frequency range $[88,89]$. Dielectric constant value is high at low-frequency range and low at high-frequency range because of different types of polarization as said above explanation, when at high-frequency range, the electric dipoles cannot follow the frequency of applied field and dipoles cannot shift their orientation sufficiently fast when frequency is high [90, 91]. The dielectric medium has conducting grains which operate at higher frequencies and poor conducting grain boundaries which are operating at lower frequencies, while frequency applied the charge carriers are assembled at grain boundaries, so polarization occurs with high dielectric constant and 


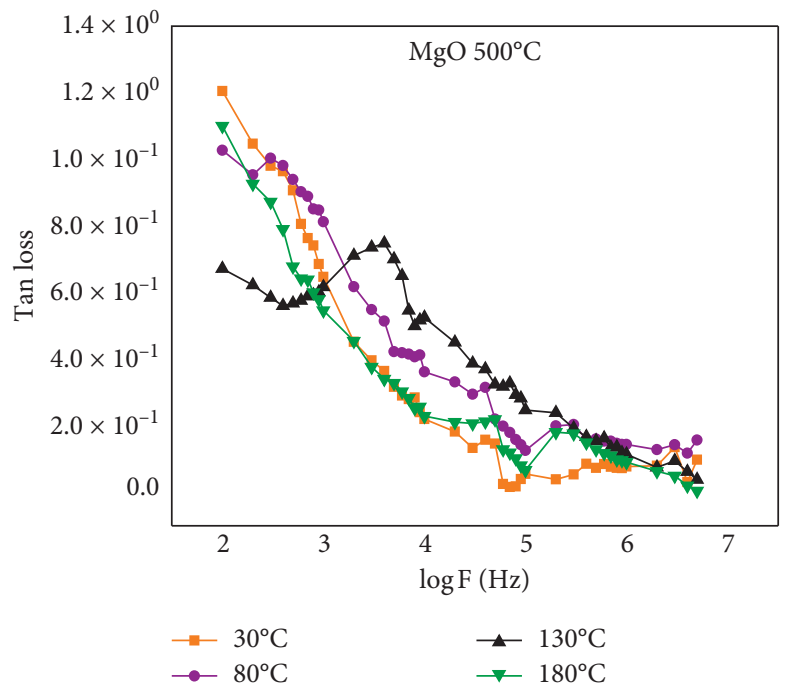

(a)

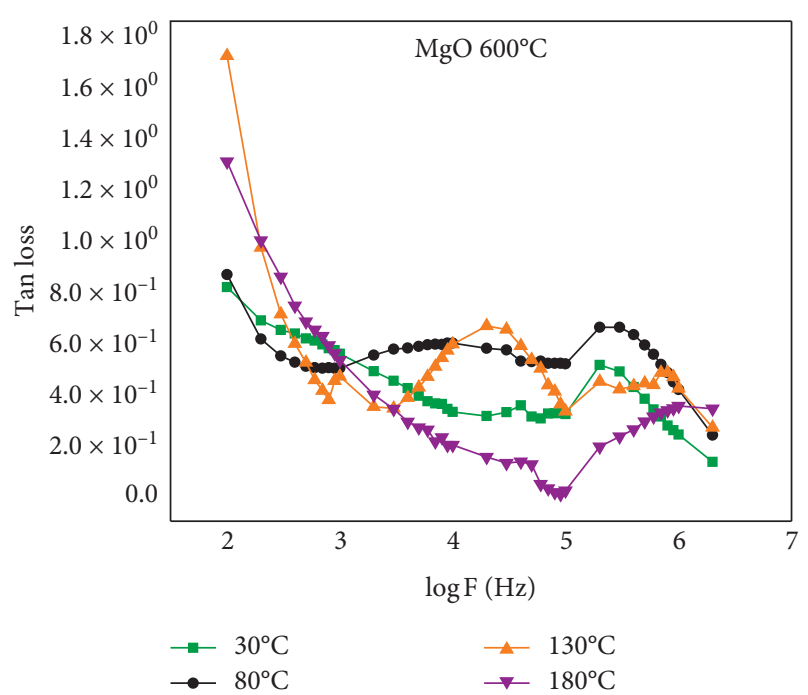

(b)

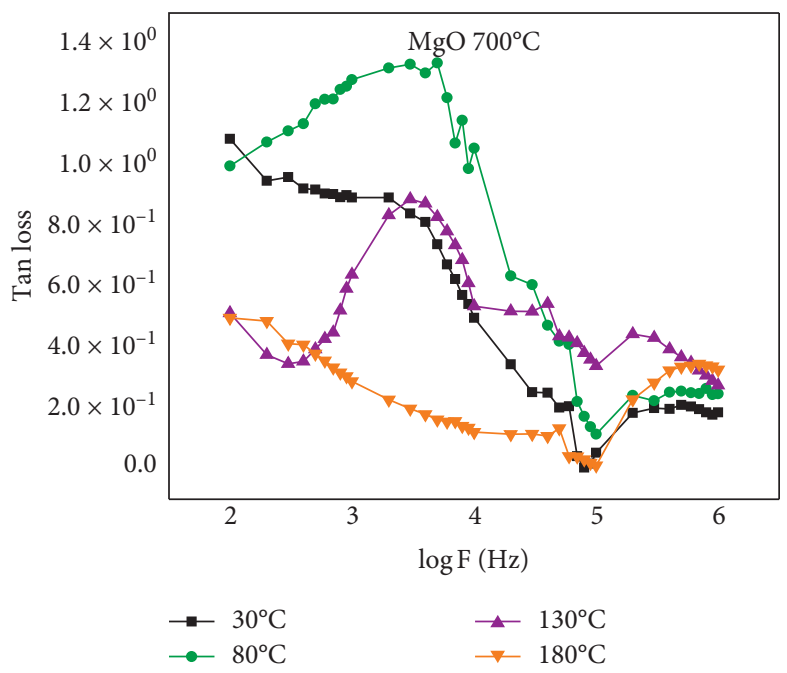

(c)

Figure 16: Tan loss of $\mathrm{MgO}$ nanoparticles at $500^{\circ} \mathrm{C}(\mathrm{a}), 600^{\circ} \mathrm{C}(\mathrm{b})$, and $700^{\circ} \mathrm{C}$ (c) with different temperatures.

polarization decreases while frequency value increases, so it has constant value at high frequency since the springing of electrons cannot cope with AC fields.

4.9. Imaginary Part of Dielectric Constant $\left(\varepsilon^{\prime \prime}\right)$. The tan loss decreased with frequency increases, the same trend has followed at all the temperatures due to thermal-activated charges accumulated of charge carriers and space charge polarization. The imaginary part of the dielectric constant value is large at the lowfrequency range as shown in Figures 15(a)-15(c). The polarization mechanism, defects, and thermally activated mobile ion conduction might be the reason for the fast-rising trend of the imaginary part of dielectric constant at lower frequencies with the thermally activated conduction of mobile ions [89].

4.10. Tan Loss. The tan loss is high at low frequency and low at high frequency due to surface polarization has reached constant value and electrons were unable to follow AC signal, so value is high at low frequency, and at high frequency, it has disappeared. The tan loss is shown in Figures 16(a)-16(c). At moderate and low frequencies, polarization is high, whereas at high frequencies, charges could not follow the AC signals [88]. Due to the domination of conducting grains, the resistivity comes down, so the loss arises and saturated at high frequency, and it obeys Koop's law. The tan loss is given by the relation (2):

$$
\text { Tan loss }=\varepsilon^{\prime} / \varepsilon^{\prime \prime}
$$

4.10.1. AC Conductivity Studies. The frequency-dependent AC conductivity of MgO nanopowder has been studied for all the three samples, and the graph has been plotted between frequency and conductivity as shown in Figures 17(a)-17(c). The AC conductivity is maximum at higher temperatures with high frequency, and the same trend has been followed 


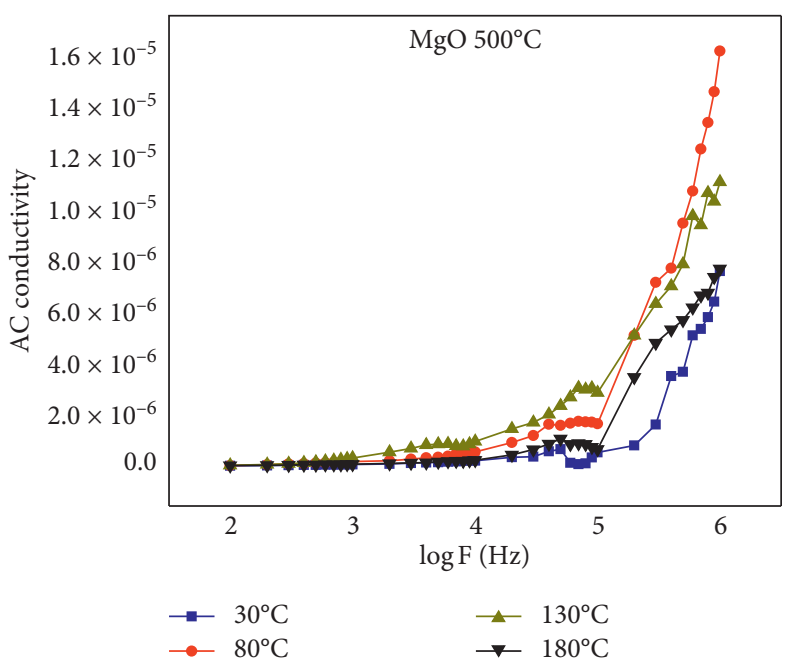

(a)

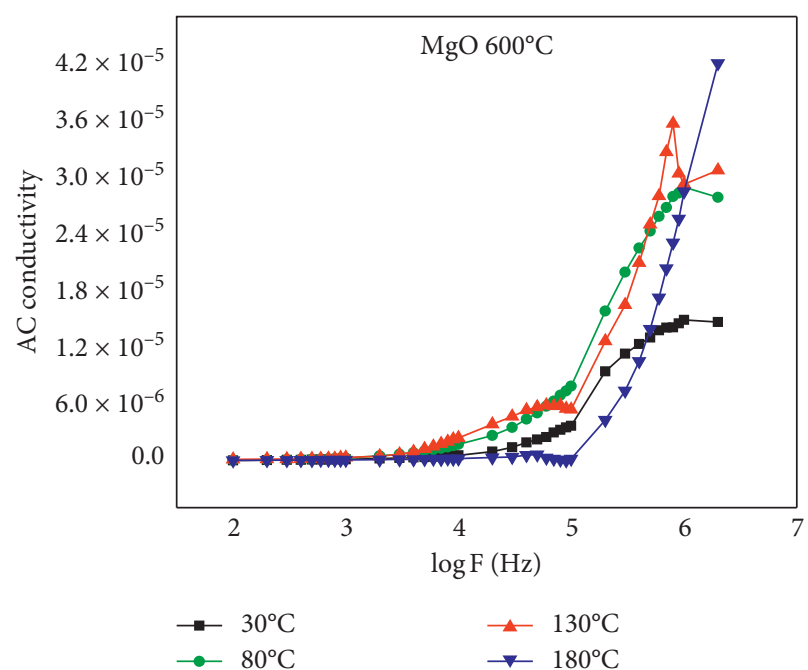

(b)

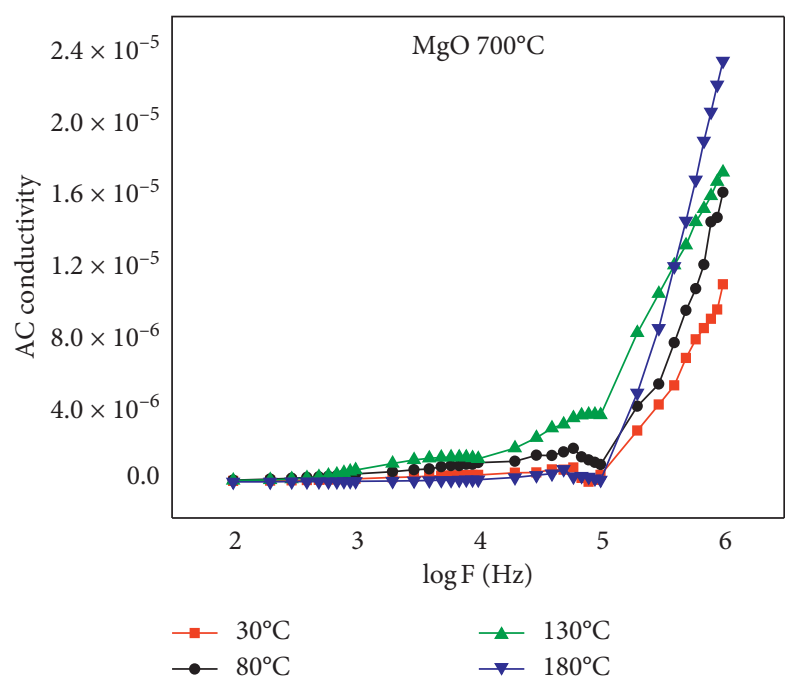

(c)

Figure 17: AC conductivity of $\mathrm{MgO}$ nanoparticles at $500^{\circ} \mathrm{C}(\mathrm{a}), 600^{\circ} \mathrm{C}(\mathrm{b})$, and $700^{\circ} \mathrm{C}$ (c) with different temperatures.

by all the samples of $\mathrm{MgO}$ nanoparticles due to charge carrier and hopping electrons also increases [92]. Moreover, it obeys the Maxwell-Wagner two-layer model according to this conductivity increases gradually along with frequency [93]. Due to polarization effects at electrode and electrolyte interface at low frequency, the variation of conductivity has occurred and all the values have merged at lower frequency owing to grains and grain boundaries which are more active, at low temperature fewer charge carriers are available, and less hoping electrons might be the reason for low conduction at low frequency $[92,93]$.

AC conductivity was calculated using the relation given as follows:

$$
\sigma=2 \pi f \varepsilon \varepsilon_{0} \tan \delta,
$$

where $\varepsilon_{0}$ is the permittivity of free space $\left(8.854 \times 10^{-12} \mathrm{~F} / \mathrm{m}\right)$.

\subsection{Complex Spectroscopy and Impedance Analysis}

4.11.1. Impedance Analysis $\left(Z^{\prime}\right.$ and $\left.Z^{\prime \prime}\right)$. Complex impedance $\left(Z^{*}=Z^{\prime}+i \cdot Z^{\prime \prime \prime \prime}\right)$ has been analyzed at different temperatures on both sides of the relaxation peak. The frequency and temperature dependence of real part of impedance ( $\left.z^{\prime}\right)$ and imaginary part of impedance has been studied using the formulism given as follows: 


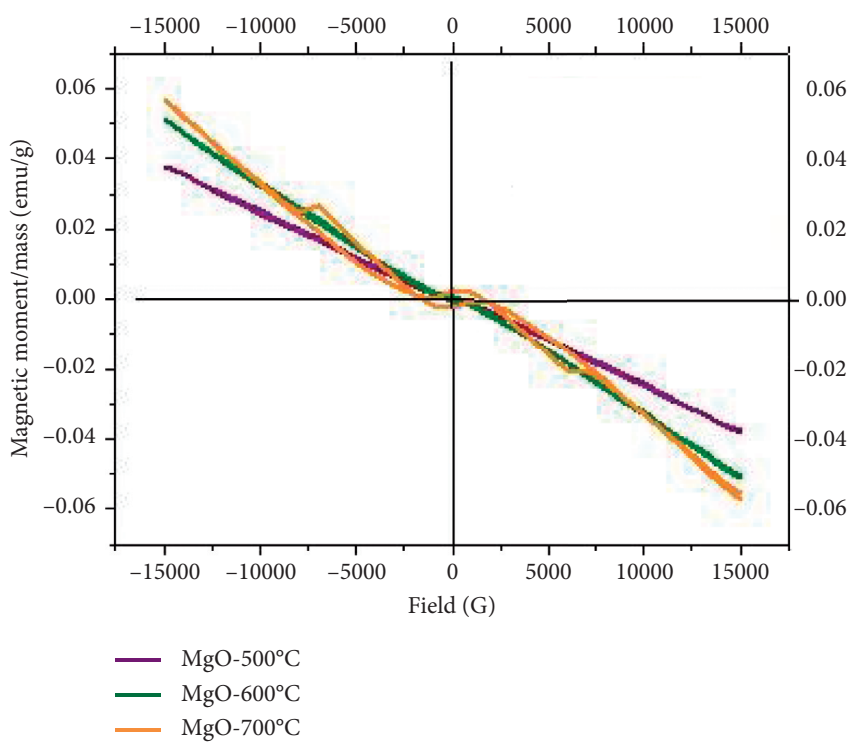

Figure 18: $\mathrm{M}-\mathrm{H}$ curve of $\mathrm{MgO}$ nanoparticles at the room temperature.

$$
\begin{aligned}
& Z^{\prime}=g /\left(C_{p}^{2} \omega^{2}+G^{2}\right) \\
& Z^{\prime \prime}=C p \omega /\left(C_{p}^{2} \omega^{2}+G\right),
\end{aligned}
$$

where $\omega$ is the $2 \pi \mathrm{f}, G$ is the conductance, and $C p$ is the static capacitance of materials.

4.12. Real Part of Impedance $\left(Z^{\prime}\right)$. The increasing trend of frequency and temperature decreases the real part of impedance value owing to space charge effect and the values saturated at high frequency as shown in supplementary information Figures S1a, S1c, and S1e, which has meant an increase of conductivity with frequency. At high frequency, the part of impedance value has merged due to the release of space charge and owing to the reduction of barrier properties or accumulation of charges at the electrode surface along with the rise of temperature [75, 94]. The decreasing trend of $Z^{\prime}$ value at high frequency is almost low in all the samples.

4.13. Imaginary Part of Impedance ( $z$ "). Oxygen vacancies in metal oxides and relaxation processes of materials are being the reason for the frequency-dependent imaginary part of impedance shifted to a higher frequency with an increase in temperature. When high temperatures are met, all the values are saturated and merged at higher frequency $[75,94]$. The imaginary part of impedance is shown in supplementary information Figures S1b, S1d, and S1f.

4.14. Cole-Cole Plot or Nyquist Plot. The graph was drawn between the real part of impedance $\left(Z^{\prime}\right)$ and the imaginary part of impedance $\left(Z^{\prime \prime}\right)$ as shown in supplementary information Figures S2a, S2b, and S2c. From Figure S2, it can be seen that slightly semicircle with distinct radii appears at the low frequency due to grain boundaries [75, 93, 94]. Semicircle decreases with increasing temperature due to the negative temperature coefficient of materials which are promising materials for thermistor applications.

4.15. Complex Electric Modulus Analysis. The real part of the electric modulus and imaginary part of electric modulus are shown in supplementary information Figures S3 and S4a, S4b, S4c, S4d and S4e, and S4f, and all are frequency-dependent. This technique quite uses full to find the relaxation time and relaxation mechanism at the metal oxides.

4.16. Real Part of Electric Modulus. Electric modulus values are high at a higher frequency and at almost zero at the lower frequency which implies that electronic polarization is none [92]. The real part of the electric modulus is shown in supplementary information Figures S3a, S3b, and S3c.

4.17. Imaginary Part of Electric Modulus. This imaginary part of electric modulus was studied, and it explains about high conduction loss owing to electric modulus increases with the increasing trend of frequency. Peaks appearing here shifted to a higher frequency because the charge carriers transported from long-range to short-range mobility with the increase of temperature [92]. Moreover, $\mathrm{M}^{\prime \prime}$ peaks shifted to higher frequencies, so we conclude that it depends on temperature and obeys hopping type mechanism for electrical conduction [92]. The imaginary part of the electric modulus spectra is shown in supplementary information Figures S4d, S4e, and S4f.

4.18. Complex Electric Modulus $\left(M^{\prime}\right.$ vs $\left.M^{\prime \prime}\right)$. The complex electric modulus spectra are shown in supplementary information Figures S5g, S5h, and S5i with different temperatures $\left(30-230^{\circ} \mathrm{C}\right)$. From the graph, we could observe that semicircles have been formed because the grain and grain boundaries might be the reason for the conduction of the materials. At the higher frequencies and temperature, the semicircle has been disappeared on account of hopping of ions [75, 92-94].

\subsection{9. $M-H$ Loop Characterization (Magnetic Property).} Room temperature magnetization measurements were carried out where vibrating sample magnetometer (VSM) was employed for analysis. Magnetic property of $\mathrm{MgO}$ nanoparticles studied from $\mathrm{M}-\mathrm{H}$ curves is shown in Figure 18 , and it is observed that all the $\mathrm{MgO}$ nanoparticles exhibited room temperature diamagnetism at 500 and $600^{\circ} \mathrm{C}$ and room temperature; week or dilute ferromagnetism has been observed from the sample while annealed at $700^{\circ} \mathrm{C}$. It is diamagnetic in nature at room temperature for the two samples of $\mathrm{MgO}$ nanopowder due to decreased number of oxygen vacancies [52, 74]. While increasing calcination temperature, the oxygen vacancies can be improved; hence, the defect sides at the surface of the $\mathrm{MgO}$ nanoparticles have been increased. Panchakarla et al. and Pathak et al. have 
reported previously that the diamagnetic nature oxides exhibit RTFM due to defects (oxygen vacancies) present at the surface of the nanoparticles grains $[95,96]$. Many reports have suggested that the room temperature ferromagnetism has been observed at the nanoscale nonmagnetic metal oxides due to anionic or cationic vacancy or size of the nanoparticles or annealing and anisotropy nature of nanomaterials [97-101]. Herein, the nanoparticles at the annealed temperature $700^{\circ} \mathrm{C}$ show very week ferromagnetic nature at ambient conditions with saturation magnetization value $\left(M_{\mathrm{s}}\right)$ of $57.004 \mathrm{E}^{-3} \mathrm{emu} / \mathrm{g}$ and coercivity value $\left(H_{\mathrm{ci}}\right)$ is 1604.5 Oe owing to the oxygen vacancies ( $\mathrm{F}^{+}$centers) have been increased with increasing annealing temperature, and while comparing with photoluminescence spectra of $\mathrm{MgO}$ nanoparticles, it has strong green, blue, and violet emissions. The violet and blue emissions occur on the surface of the $\mathrm{MgO}$ nanoparticles due to oxygen vacancies $\left(V_{\mathrm{o}}\right)$; hence, room temperature ferromagnetism (RTFM) has been observed in diamagnetic oxides owing to defect-induced magnetism. Rao et al. and $\mathrm{Hu}$ et al. have reported that the oxygen vacancy $\left(\mathrm{F}^{+}\right)$is the major responsible for presence of hysteresis and it shows FM or dilute magnetism in $\mathrm{MgO}$ nanoparticles, while temperature increases, it increases the $\mathrm{F}^{2+}$ centers which could be the reason for arising FM in $\mathrm{MgO}$ nanoparticles [96, 100, 102, 103].

\section{Conclusion}

Eco-friendly, surfactant-free, low-cost $\mathrm{MgO}$ nanoparticles were prepared successfully from the green route at different annealing temperatures. Phase purity was observed by PXRD with rising calcination temperatures where the crystal phase has not a significant change. Heat treatment has revealed that phase transition and weight loss occur due to the reduction of the hydroxyl group. FTIR studies have confirmed the formation of $\mathrm{MgO}$ nanoparticles. Diamagnetism property has been observed in $\mathrm{MgO}$ nanoparticles. Dielectric dispersion has been observed due to space charge polarization due to grain boundaries, and linear variation in dielectric constant and dielectric loss leads to $\mathrm{MgO}$ is a good linear dielectric ceramic and potential candidate for capacitor applications, and it is explained with the Maxwell-Wagner model. Complex impedance analysis and AC conductivity of samples rise trend with increasing frequency due to grain resistant better matches with $\mathrm{CBH}$ (correlated barrier hopping) model, and Nyquist plot and Complex modulus plot exhibit non-Debye relaxation type. SEM and TEM studies showed the less aggregated, polycrystalline nature of nanoparticles which were nano in size with distinct morphology with different calcination temperatures. Photoluminescence studies have revealed that the $\mathrm{MgO}$ nanoparticles exhibited multicolor emission in UV and Visible regions due to various defect centers ( $\mathrm{F}$ centers), so it could be a potential candidate in optoelectronic devices and UV detectors since absorbance at UV region and it was a wide band gap material.

\section{Data Availability}

The data used to support the findings of this study are included in this article.

\section{Conflicts of Interest}

The authors declare that they have no conflicts of interest.

\section{Acknowledgments}

The authors would like to show their gratitude to Dr. S. Kalainathan, Senior Professor, Centre for Nanotechnology Research, VIT, Vellore, Tamil Nadu, India, for his valuable guidance during the course of their research particularly in dielectric studies and TEM studies and are immensely grateful to Dr. Venu Reddy, HOD, Department of Chemistry and Nanotechnology Research Centre, SRKR Engineering College, Bhimavaram, 534204, Andhra Pradesh, India, for his timely help. The authors sincerely thank Dr. K. Nehru, Associate Professor, Department of Chemistry, Anna University, Trichy, and Dr. Arul Mozhi, Associate Professor and Head, Petrochemical Technology, Anna University, Trichy, for their kind cooperation during their lab work.

\section{Supplementary Materials}

Figure. S1: real part and imaginary part of impedance ( $z$ ' and $\left.\mathrm{z}^{\prime \prime}\right)$ at $500^{\circ} \mathrm{C}(\mathrm{a}, \mathrm{b}), 600^{\circ} \mathrm{C}(\mathrm{c}, \mathrm{d})$, and $700^{\circ} \mathrm{C}(\mathrm{e}, \mathrm{f})$. Figure. $\mathrm{S} 2$ : Nyquist plot of $500^{\circ} \mathrm{C}, 600^{\circ} \mathrm{C}$, and $700^{\circ} \mathrm{C}(\mathrm{a}, \mathrm{b}, \mathrm{c})$. Figure. S3: real part of electric modulus at $500^{\circ} \mathrm{C}, 600^{\circ} \mathrm{C}$, and $700^{\circ} \mathrm{C}(\mathrm{a}, \mathrm{b}$, c). Figure. S4: imaginary part of electric modulus of $\mathrm{MgO}$ nanoparticles at $500^{\circ} \mathrm{C}, 600^{\circ} \mathrm{C}$, and $700^{\circ} \mathrm{C}(\mathrm{d}, \mathrm{e}, \mathrm{f})$. Figure. S5: $\mathrm{M}^{\prime}$ vs $\mathrm{M}^{\prime \prime}$ of $\mathrm{MgO}$ nanoparticles at $500^{\circ} \mathrm{C}, 600^{\circ} \mathrm{C}$, and $700^{\circ} \mathrm{C}$ (g, h, i). Figure. S6: graphical abstract. . (Supplementary Materials)

\section{References}

[1] J. Gangwar, B. K. Gupta, and A. K. Srivastava, "Prospects of emerging engineered oxide nanomaterials and their applications," Defence Science Journal, vol. 66, no. 4, pp. 323-340, 2016.

[2] Z. Nie, A. Petukhova, and E. Kumacheva, "Properties and emerging applications of self-assembled structures made from inorganic nanoparticles," Nature Nanotechnology, vol. 5, no. 1, pp. 15-25, 2010.

[3] X. Wang, L. Yu, P. Hu, and F. Yuan, "Synthesis of singlecrystalline hollow octahedral NiO," Crystal Growth \& Design, vol. 7, no. 12, pp. 2415-2418, 2007.

[4] Z. Chen, D. Pan, Z. Li et al., "Recent advances in tin dioxide materials: some developments in thin films, nanowires, and nanorods," Chemical Reviews, vol. 114, no. 15, pp. 7442-7486, 2014.

[5] J. Gangwar, K. K. Dey, P. Komal, S. K. Tripathi, and A. K. Srivastava, "Microstructure, phase formations and optical bands in nanostructured alumina," Advanced Materials Letters, vol. 2, no. 6, pp. 402-408, 2011.

[6] W. Zheng, P. Zu, R. Dai, and L. Zhong, "Nanobelts of semiconducting oxides," Science, vol. 291, no. (5510, pp. 1947-1949, 2001. 
[7] P. M. Valencia, O. C. Farokhzad, R. Karnik, and R. Langer, "Microfluidic technologies for accelerating the clinical translation of nanoparticles," Nature Nanotechnology, vol. 7, no. 10, pp. 623-629, 2012.

[8] J. Gangwar, A. K. Srivastava, S. K. Tripathi, M. Wan, and R. R. Yadav, "Strong enhancement in thermal conductivity of ethylene glycol-based nanofluids by amorphous and crystalline $\mathrm{Al}_{2} \mathrm{O}_{3}$ nanoparticles," Applied Physics Letters, vol. 105, 2014.

[9] S. Shang, K. Xue, D. Chen, and X. Jiao, "Preparation and characterization of rose-like $\mathrm{NiO}$ nanostructures," CrystEngComm, vol. 13, no. 16, pp. 5094-5099, 2011.

[10] L.-S. Zhong, J.-S. Hu, H.-P. Liang, A.-M. Cao, W.-G. Song, and L.-J. Wan, "Self-assembled 3D flowerlike iron oxide nanostructures and their application in water treatment," Advanced Materials, vol. 18, no. 18, pp. 2426-2431, 2006.

[11] S. Baker, D. Rakshith, S. K. Kumara et al., "Plants: emerging as nanofactories towards facile route in synthesis of nanoparticles," BioImpacts, vol. 3, no. 3, pp. 111-117, 2013.

[12] V. Kumar and S. K. Yadav, "Plant-mediated synthesis of silver and gold nanoparticles and their applications," Journal of Chemical Technology \& Biotechnology, vol. 84, no. 2, pp. 151-157, 2009.

[13] D. Mandal, M. E. Bolander, D. Mukhopadhyay, G. Sarkar, and P. Mukherjee, "The use of microorganisms for the formation of metal nanoparticles and their application," Applied Microbiology and Biotechnology, vol. 69, no. 5, pp. 485-492, 2006.

[14] D. Cui and H. Gao, "This article has been retracted. advance and prospect of bionanomaterials," Biotechnology Progress, vol. 19, no. 3, pp. 683-692, 2003.

[15] H. Bar, D. K. Bhui, G. P. Sahoo, P. Sarkar, S. P. De, and A. Misra, "Green synthesis of silver nanoparticles using latex of Jatropha curcas," Colloids and Surfaces A: Physicochemical and Engineering Aspects, vol. 339, no. 1-3, pp. 134-139, 2009.

[16] S. S. Shankar, A. Ahmad, R. Pasricha, and M. Sastry, "Bioreduction of chloroaurate ions by Geranium leaves and its endophytic fungus yields gold nanoparticles of different shapes," Journal of Materials Chemistry, vol. 13, no. 7, pp. 1822-1826, 2003.

[17] V. Armendariz, I. Herrera, J. R. peralta-videa et al., "Size controlled gold nanoparticle formation by Avena sativa biomass: use of plants in nanobiotechnology," Journal of Nanoparticle Research, vol. 6, no. 4, pp. 377-382, 2004.

[18] V. Armendariz, J. L. Gardea-Torresedey, J. Gonzalez, I. Herrera, M. Jose-Yacama, and J. G. Parsons, "Gold nanoparticle formation by oat and wheat biomassses," in in Proceedings of the Waste Resolution Technologies, pp. 224-232, Carl R. Ice College of Engineering, Manhattan, KS, USA, 2002.

[19] J. L. Gardea-Torresedey, V. Armendariz, I. Herreira et al., "Binding of silver (I) ions by alfalfa biomass (Medicago sativa): batch $\mathrm{pH}$, time, temperature, and ionic strength studies," Journal of Hazardous Substance Research, vol. 4, pp. 1-15, 2003.

[20] J. L. Gardea-Torresdey, E. Gomez, J. R. Peralta-Videa, J. G. Parsons, H. Troiani, and M. Jose-Yacaman, "Alfalfa sprouts: a natural source for the synthesis of silver nanoparticles," Langmuir, vol. 19, no. 4, pp. 1357-1361, 2003.

[21] J. Huang, C. Chen, N. He et al., "Biosynthesis of silver and gold nanoparticles by novel sun-dried Cinnamomum camphora leaf," Nanotechnology, vol. 18, pp. 105-106, 2007.

[22] V. Parashar, R. Parashar, B. Sharma, and A. C. Pandey, "Parthenium leaf extract mediated synthesis of silver nanoparticles: a novel approach towards weed utilization," Digest Journal of Nanomaterials and Biostructures, vol. 4, pp. 45-50, 2009.

[23] U. K. Parashar, P. S. Saxena, and A. Shrivastava, "Bio inspired synthesis of silver nanoparticles," Digest Journal of Nanomaterials and Biostructures, vol. 4, pp. 159-166, 2009.

[24] M. Rai and A. Yadav, "Plants as potential synthesiser of precious metal nanoparticles: progress and prospects," IET Nanobiotechnology, vol. 7, no. 3, pp. 117-124, 2013.

[25] P. T. Anastas and J. B. Zimmerman, Green Nanotechnology Why We Need A Green Nano Award 542 and How to Make It Happen, Woodrow Wilson International 543 Center for Scholars, Washington, DC, USA, 2007.

[26] K. M. Amit and Y. Chisti, "Synthesis of metallic nanoparticles using plant extracts," Biotechnology Advances, vol. 31, pp. 346-356, 2013.

[27] K. S. Mukunthan and S. Balaji, "Cashew apple juice (anacardium occidentaleL.) speeds up the synthesis of silver nanoparticles," International Journal of Green Nanotechnology, vol. 4, no. 2, pp. 71-79, 2012.

[28] N. John Sushma, D. Prathyusha, G. Swathi et al., "Facile approach to synthesize magnesium oxide nanoparticles by using Clitoria ternatea-characterization and in vitro antioxidant studies," Applied Nanoscience, vol. 6, no. 3, pp. 437-444, 2016.

[29] K. Ganapathi Rao, C. H. Ashok, K. Venkateswara Rao, C. H. Shilpa Chakra, and A. Akshaykranth, "Eco-friendly synthesis of $\mathrm{MgO}$ nanoparticles from orange fruit," Waste International Journal of Advanced Research in Physical Science (IJARPS), vol. 2, pp. 1-6, 2015.

[30] R. Dobrucka, "Synthesis of MgO nanoparticles using Artemisia abrotanum herba extract and their antioxidant and photocatalytic properties," Iranian Journal of Science and Technology, Transactions A: Science, vol. 42, no. 2, pp. 547555, 2018.

[31] P. Sugirtha, R. Divya, R. Yedhukrishnan et al., "Green synthesis of magnesium oxide nanoparticles using Brassica oleracea and Punica granatum Peels and their anticancer and photocatalytic activity," Asian Journal of Chemistry, vol. 27, no. 7, pp. 2513-2517, 2015.

[32] G. Sharma, R. Soni, and N. D. Jasuja, "Phytoassisted synthesis of magnesium oxide nanoparticles with Swertia chirayaita," Journal of Taibah University for Science, vol. 11, no. 3, pp. 471-477, 2017.

[33] S. K. Moorthy, C. Ashok, K. V. Rao, and C. Viswanathan, "Synthesis and characterization of $\mathrm{MgO}$ nanoparticles by neem leaves through green method," Materials Today: Proceedings, vol. 2, no. 9, pp. 4360-4368, 2015.

[34] A. Anantharaman, S. Sathyabhama, and M. George, "Green synthesis of magnesium oxide nanoparticles using Aloe Vera and its applications," IJSRD-International Journal for Scientific Research \& Development, vol. 4, no. 9, 2016.

[35] N. Ashwini Anantharama, K. S. Sheethal, and G. Mary, "Green synthesis and its applications of magnesium oxide nanoparticles from the seeds of lepedium sativum," International Journal of Recent Scientific Research, vol. 7, pp. 14029-14032, 2016.

[36] L. Umaralikhan and M. Jamal Mohamed Jaffar, "Green synthesis of $\mathrm{MgO}$ nanoparticles and it antibacterial activity," Iranian Journal of Science and Technology, Transactions A: Science, vol. 42, no. 2, pp. 477-485, 2018.

[37] J. Suresh, R. Yuvakkumar, M. Sundrarajan, and S. I. Hong, "Green synthesis of magnesium oxide nanoparticles," Advanced Materials Research, vol. 952, pp. 141-144, 2014. 
[38] J. Jeevanandam, Y. S. Chan, and M. K. Danquah, "Biosynthesis and characterization of $\mathrm{MgO}$ nanoparticles from plant extracts via induced molecular nucleation," New Journal of Chemistry, vol. 41, no. 7, pp. 2800-2814, 2017.

[39] N. Jayarambabu, B. Siva Kumari, K. Venkateswara Rao, and Y. T. Prabhu, "Enhancement of growth in maize by biogenicsynthesized mgo nanoparticles," International Journal of Pure and Applied Zoology, vol. 4, pp. 262-270, 2016.

[40] D. Kumar, L. S. Reddy Yadav, K. Lingaraju et al., "Combustion synthesis of $\mathrm{MgO}$ nanoparticles using plant extract: structural characterization and photoluminescence studies," AIP Conference Proceedins, vol. 1665, pp. 050145-1-0501453, 2015.

[41] K. Ramanujam and M. Sundrarajan, "Antibacterial effects of biosynthesized $\mathrm{MgO}$ nanoparticles using ethanolic fruit extract of Emblica officinalis," Journal of Photochemistry and Photobiology B: Biology, vol. 141, pp. 296-300, 2014.

[42] C. Ramachandran, K. V. Peter, and P. K. Gopalakrishnan, "Drumstick (Moringa oleifera): a multipurpose Indian vegetable," Economic Botany, vol. 34, no. 3, pp. 276-283, 1980.

[43] M. U. Dahot, "Vitamin contents of flowers and seeds of Moringa Oleifera," Pakistan Journal of Biochemistry, vol. 21, pp. 1-24, 1988.

[44] F. Anwar, S. Latif, M. Ashraf, and A. H. Gilani, "Moringa oleifera: a food plant with multiple medicinal uses," Phytotherapy Research, vol. 21, no. 1, pp. 17-25, 2007.

[45] R. AliS. W. Joo et al., "Eco-friendly synthesis of magnesium oxide nanoparticles using Arabic gum," Journal of Applied Chemical Research, vol. 12, pp. 8-15, 2018.

[46] I. W. Sutapa, A. Wahid Wahab, P. Taba, and N. L. Nafie, "Dislocation, crystallite size distribution and lattice strain of magnesium oxide nanoparticles," Journal of Physics: Conference Series, vol. 979, Article ID 012021, 2018.

[47] T. Boningari, S. N. R. Inturi, V. I. Manousiouthakis, and P. G. Smirniotis, "Facile synthesis of flame spray pyrolysisderived magnesium oxide nanoparticles for $\mathrm{CO}_{2}$ sorption: effect of precursors, morphology, and structural properties," Industrial \& Engineering Chemistry Research, vol. 57, no. 28, pp. 9054-9061, 2018.

[48] J. JeeVanandam, Y. S. Chan, and Y. H. Ku, "Aqueous Eucalyptus globulus leaf extract-mediated biosynthesis of $\mathrm{MgO}$ nanorods," Applied Biological Chemistry, vol. 61, no. 2, pp. 197-208, 2018.

[49] Y. Zheng, L. Cao, G. Xing, Z. Bai, J. Huang, and Z. Zhang, "Microscale flower-like magnesium oxide for highly efficient photocatalytic degradation of organic dyes in aqueous solution," RSC Advances, vol. 9, no. 13, pp. 7338-7348, 2019.

[50] K. Mageshwari and R. Sathyamoorthy, "Studies on photocatalytic performance of $\mathrm{MgO}$ nanoparticles prepared by wet chemical method," Transactions of the Indian Institute of Metals, vol. 65, no. 1, pp. 49-55, 2012.

[51] S. F. Bdewi, O. G. Abdullah, B. K. Aziz, and A. A. R. Mutar, "Synthesis, structural and optical characterization of $\mathrm{MgO}$ nanocrystalline embedded in PVA matrix," Journal of Inorganic and Organometallic Polymers and Materials, vol. 26, no. 2, pp. 326-334, 2016.

[52] A. Khamkongkaeo, N. Mothaneeyachart, P. Sriwattana et al., "Ferromagnetism and diamagnetism behaviors of $\mathrm{MgO}$ synthesized via thermal decomposition method," Journal of Alloys and Compounds, vol. 705, pp. 668-674, 2017.

[53] R. Baddour-Hadjean, J.-P. Pereira-Ramos, and P. Ramos, "Raman microspectrometry applied to the study of electrode materials for lithium batteries," Chemical Reviews, vol. 110, no. 3, pp. 1278-1319, 2010.

[54] S. R. Soniya and V. Manikantan Nair, "Synthesis and characterization of nanostructured $\mathrm{Mg}(\mathrm{OH})_{2}$ and $\mathrm{MgO}$," International Journal of Science and Research (IJSR), vol. 5, no. 2, pp. 197-203, 2016.

[55] J. E. Rodrigues, D. M. Bezerra, and A. C. Hernandes, "Calculation of the optical phonons in ordered $\mathrm{Ba}_{2} \mathrm{MgWO}_{6}$ perovskite using short-range force field model," Journal of Raman Spectroscopy, vol. 49, no. 11, pp. 1822-1829, 2018.

[56] G. H. Jaffari, A. Tahir, M. Bah, A. Ali, A. S. Bhatti, and S. I. Shah, "Study of surface-active modes and defects in single-phase Li-incorporated $\mathrm{MgO}$ nanoparticles," The Journal of Physical Chemistry C, vol. 119, no. 50, pp. 28182-28189, 2015.

[57] P. Swatirupa, K. S. Saroj, and K. M. Birendra, "Vibrational spectroscopic study for qualitative assessment of Mn-oxide ore," Resource Geology, vol. 66, pp. 12-23, 2015.

[58] T. Athar, A. Hakeem, and W. Ahmed: Advanced science letters, American Scientific Publishers, pp. 27-29, 2012.

[59] T. Athar, A. Deshmukh, and W. Ahmed, "Synthesis of MgO nanopowder via non aqueous sol-gel method," Advanced Science Letters, vol. 5, pp. 1-3, 2015.

[60] B. Deepa and V. Rajendran, "Investigation of organic solvents assisted nano magnesium oxide nanoparticles and their structural, morphological, optical and antimicrobial performance," Materials Research Express, vol. 5, no. 1, Article ID 015033, 2018.

[61] N. Pathak, P. S. Ghosh, S. K. Gupta, R. M. Kadam, and A. Arya, "Defects induced changes in the electronic structures of $\mathrm{MgO}$ and their correlation with the optical properties: a special case of electron-hole recombination from the conduction band," RSC Advances, vol. 6, no. 98, pp. 96398-96415, 2016.

[62] W. B. Ayinde, M. W. Gitari, M. Muchindu, and A. Samie, "Biosynthesis of ultrasonically modified Ag-MgO nanocomposite and its potential for antimicrobial activity," Journal of Nanotechnology, vol. 2018, Article ID 9537454, 10 pages, 2018.

[63] Y. G. Zhang, H. Y. He, and B. C. Pan, "Structural features and electronic properties of $\mathrm{MgO}$ nanosheets and nanobelts," The Journal of Physical Chemistry C, vol. 116, no. 43, pp. 23130-23135, 2012.

[64] A. Maurya and N. Bhatia, "Microwave assisted sol gel synthesis of magnesium oxide ( $\mathrm{MgO})$," International Journal of Engineering Research and Development, vol. 13, no. 8, pp. 1-6, 2017.

[65] J. J. Bean, M. Saito, S. Fukami et al., "Atomic structure and electronic properties of $\mathrm{MgO}$ grain boundaries in tunnelling magnetoresistive devices," Scientific Reports, vol. 7, no. 1, Article ID 45594, 2017.

[66] U. Schönberger and F. Aryasetiawan, "Bulk and surface electronic structures of MgO," Physical Review B, vol. 52, no. 12, pp. 8788-8793, 1995.

[67] H. R. Moon, J. J. Urban, and D. J. Milliron, "Size-Controlled synthesis and optical properties of monodisperse colloidal magnesium oxide nanocrystals," Angewandte Chemie International Edition, vol. 48, no. 34, pp. 6278-6281, 2009.

[68] V. Atasie, A. Okeafor, and D. Nwude, "Biogenic synthesis of magnesium oxide nanoparticles using Manihot esculenta (Crantz) leaf extract," International Nano Letters, vol. 10, pp. 43-48, 2020.

[69] I. Muneer, M. A. Farrukh, and R. Raza, "Influence of annealing temperature on the physical and photoelectric 
properties of $\mathrm{Gd} / \mathrm{Fe} 1.727 \mathrm{Sn} 0.205 \mathrm{O} 3$ nanoparticles for solid oxides fuel cell application," Journal of Sol-Gel Science and Technology, vol. 94, no. 1, pp. 98-108, 2020.

[70] A. S. Keiteb, E. Saion, A. Zakaria, and N. Soltani, "Structural and optical properties of zirconia nanoparticles by thermal treatment synthesis," Journal of Nanomaterials, vol. 2016, Article ID 1913609, 6 pages, 2016.

[71] N. Badar, N. F. Chayed, R. Roshidah, N. Kamarudin, and N. Kamarulzaman, "Band gap energies of magnesium oxide nanomaterials synthesized by the sol-gel method," Advanced Materials Research, vol. 545, pp. 157-160, 2012.

[72] H. Y. Zahran, S. S. Shneouda, I. S. Yahia, and F. El-Tantawy, "Facile and rapid synthesis of nanoplates $\mathrm{Mg}(\mathrm{OH})_{2}$ and $\mathrm{MgO}$ via Microwave technique from metal source: structural, optical and dielectric properties," Journal of Sol-Gel Science and Technology, vol. 86, no. 1, pp. 104-111, 2018.

[73] M. Bhatnagar, V. Kaushik, A. Kaushal, M. Singh, and B. R. Mehta, "Structural and photoluminescence properties of tin oxide and tin oxide: $C$ core-shell and alloy nanoparticles synthesised using gas phase technique," AIP Advances, vol. 6, no. 9, Article ID 095321, 2016.

[74] S. Sharma, T. Basu, A. Shahee, K. Singh, N. P. Lalla, and E. V. Sampathkumaran, "Complex dielectric and impedance behavior of magnetoelectric $\mathrm{Fe}_{2} \mathrm{TiO}_{5}$," Journal of Alloys and Compounds, vol. 663, pp. 289-294, 2016.

[75] S. Gowreesan and A. Ruban Kumar, "Effects of $\mathrm{Mg}^{2+}$ ion substitution on the structural and electric studies of spinel structure of $\mathrm{Co} 1-\mathrm{xMgxFe}_{2} \mathrm{O}_{4}$," Journal of Materials Science: Materials in Electronics, vol. 28, no. 6, pp. 4553-4564, 2017.

[76] S. Sharma, T. Basu, A. Shahee Dimri et al., "Room-temperature ferromagnetism in $\mathrm{Ca}$ and $\mathrm{Mg}$ stabilized cubic zirconia bulk samples and thin films prepared by pulsed laser deposition," Journal of Physics D: Applied Physics, vol. 45, no. $47,2012$.

[77] C. M. Janet, B. Viswanathan, R. P. Viswanath, and T. K. Varadarajan, "Characterization and photoluminescence properties of $\mathrm{MgO}$ microtubes synthesized from hydromagnesite flowers," The Journal of Physical Chemistry C, vol. 111, no. 28, pp. 10267-10272, 2007.

[78] J. Zhang and L. Zhang, "Intensive green light emission from MgO nanobelts," Chemical Physics Letters, vol. 363, no. 3-4, pp. 293-297, 2002.

[79] Y. Ding, G. Zhang, H. Wu, B. Hai, L. Wang, and Y. Qian, "Nanoscale magnesium hydroxide and magnesium oxide powders: control over size, shape, and structure via hydrothermal synthesis," Chemistry of Materials, vol. 13, no. 2, pp. 435-440, 2001.

[80] K. Jhansi, N. Jayarambabu, K. P. Reddy et al., "Biosynthesis of $\mathrm{MgO}$ nanoparticles using mushroom extract: effect on peanut (Arachis hypogaea L.) seed germination," 3 Biotech, vol. 7, no. 4, 2017.

[81] A. V. Borhade, K. G. Kanade, D. R. Tope, and M. D. Patil, “A Comparative study on synthesis, characterization and photocatalytic activities of $\mathrm{MgO}$ and $\mathrm{Fe} / \mathrm{MgO}$ nanoparticles," Research on Chemical Intermediates, vol. 38, no. 8, pp. 20121931-20121946, 2012.

[82] K. Kaviyarasu, E. Manikandan, J. Kennedy, and M. Maaza, "A comparative study on the morphological features of highly ordered MgO: AgO nanocube arrays prepared via a hydrothermal method," RSC Advances, vol. 5, no. 100, pp. 82421-82428, 2015.

[83] S. M. Pourmortazavi, V. Mirzajani, and K. Farhadi, “Thermal behavior and thermokinetic of double-base propellant catalyzed with magnesium oxide nanoparticles," Journal of
Thermal Analysis and Calorimetry, vol. 137, no. 1, pp. 93-104, 2019.

[84] A. Subramania, G. V. Kumar, A. R. S. Priya, and T. Vasudevan, "Polyol-mediated thermolysis process for the synthesis of $\mathrm{MgO}$ nanoparticles and nanowires," Nanotechnology, vol. 18, no. 22, Article ID 225601, 2007.

[85] C. Hai, S. Li, Y. Zhou, J. Zeng, X. Ren, and X. Li, "Roles of ethylene glycol solvent and polymers in preparing uniformly distributed MgO nanoparticles," Journal of Asian Ceramic Societies, vol. 5, no. 2, pp. 176-182, 2017.

[86] T. Athar, A. Hakeem, and W. Ahmed, "Synthesis of $\mathrm{MgO}$ nanopowder via non aqueous sol-gel method," Advanced Science Letters, vol. 7, no. 1, pp. 27-29, 2012.

[87] A. L. Gajengi, T. Sasaki, and B. M. Bhanage, "Mechanistic aspects of formation of $\mathrm{MgO}$ nanoparticles under microwave irradiation and its catalytic application," Advanced Powder Technology, vol. 28, no. 4, pp. 1185-1192, 2017.

[88] B. Yosef, Ş. Altındal, and İ. Uslu, "Dielectric properties, electrical modulus and current transport mechanisms of Au/ $\mathrm{ZnO} / \mathrm{n}$-Si structures," Progress in Natural Science: Materials International, vol. 28, pp. 325-331, 2018.

[89] T. Badapanda, R. Kumar Harichandan, S. Sekhar Nayak, A. Mishra, and S. Anwar, "Frequency and temperature dependence behaviour of impedance, modulus and conductivity of BaBi4Ti4O15 Aurivillius ceramic," Processing and Application of Ceramics, vol. 8, no. 3, pp. 145-153, 2014.

[90] A. Hashim, A. Hadi, and A. Hadi, "Synthesis and characterization of novel piezoelectric and energy storage nanocompo-sites: biodegradable materials-magnesium oxide nanoparticles," Ukrainian Journal of Physics, vol. 62, no. 12, pp. 1050-1056, 2017.

[91] S.-S. Chen, J. Hu, L. Gao et al., "Enhanced breakdown strength and energy density in PVDF nanocomposites with functionalized MgO nanoparticles," RSC Advances, vol. 6, no. 40, pp. 33599-33605, 2016.

[92] S. Gowreesan and A. Ruban Kumar, "Structural, magnetic, and electrical property of nanocrystalline perovskite structure of iron manganite $\left(\mathrm{FeMnO}_{3}\right)$," Applied Physics A, vol. 123, no. 11, p. 689, 2017.

[93] H. Joshi, S. Gowreesan, and A. R. Kumar, "Influences of $\mathrm{Ni}^{2+}$ on magnetic property and dielectric property in spinel structure of $\mathrm{Mg}$ ferrite $\left(\mathrm{Mg} 1-\mathrm{xNixFe}_{2} \mathrm{O}_{4}\right)$," Journal of $\mathrm{Ma}$ terials Science: Materials in Electronics, vol. 29, no. 4, pp. 3449-3457, 2018.

[94] M. Dimri, H. Khanduri, H. Kooskora et al., "Room-temperature ferromagnetism in $\mathrm{Ca}$ and $\mathrm{Mg}$ stabilized cubic zirconia bulk samples and thin films prepared by pulsed laser deposition," Journal of Physics D: Applied Physics, vol. 45, no. 47, 2012.

[95] L. S. Panchakarla, Y. Sundarayya, S. Manjunatha, A. Sundaresan, and C. N. R. Rao, "On the defect origin of the room-temperature magnetism universally exhibited by metal-oxide nanoparticles," ChemPhysChem, vol. 11, no. 8, pp. 1673-1679, 2010.

[96] N. Pathak, S. K. Gupta, C. L. Prajapat et al., "Defect induced ferromagnetism in $\mathrm{MgO}$ and its exceptional enhancement upon thermal annealing: a case of transformation of various defect states," Physical Chemistry Chemical Physics, vol. 19, no. 19, pp. 11975-11989, 2017.

[97] S. Phokha, J. Klinkaewnarong, S. Hunpratub, K. Boonserm, E. Swatsitang, and S. Maensiri, "Ferromagnetism in Fedoped MgO nanoparticles," Journal of Materials Science: Materials in Electronics, vol. 27, no. 1, pp. 33-39, 2016. 
[98] S. Azzaza, M. El-Hilo, S. Narayanan et al., "Structural, optical and magnetic characterizations of $\mathrm{Mn}$-doped $\mathrm{MgO}$ nanoparticles," Materials Chemistry and Physics, vol. 143, no. 3, pp. 1500-1507, 2014.

[99] D. Mishra, B. P. Mandal, R. Mukherjee, R. Naik, G. Lawes, and B. Nadgorny, "Oxygen vacancy enhanced room temperature magnetism in $\mathrm{Al}$-doped $\mathrm{MgO}$ nanoparticles," Applied Physics Letters, vol. 102, no. 18, Article ID 182404, 2013.

[100] C. N. Rao, U. T. Nakate, R. J. Choudhary, and S. N. Kale, "Defect-induced magneto-optic properties of MgO nanoparticles realized as optical-fiber-based low-field magnetic sensor," Applied Physics Letters, vol. 103, no. 15, Article ID 151107, 2013.

[101] F. Guo, X. Jiang, X. Li, X. Jia, S. Liang, and L. Qian, "Synthesis of $\mathrm{MgO} / \mathrm{Fe} 3 \mathrm{O} 4$ nanoparticles embedded activated carbon from biomass for high-efficient adsorption of malachite green," Materials Chemistry and Physics, vol. 240, Article ID 122240, 2020.

[102] S. R. Habiby, H. Esmaeili, and R. Foroutan, "Magnetically modified MgO nanoparticles as an efficient adsorbent for phosphate ions removal from wastewater," Separation Science and Technology, vol. 55, no. 11, pp. 1910-1921, 2020.

[103] J. Hu, Z. Zhang, M. Zhao, H. Qin, and M. Jiang, "Roomtemperature ferromagnetism in $\mathrm{MgO}$ nanocrystalline powders," Applied Physics Letters, vol. 93, no. 19, Article ID 192503, 2008. 